(C) 2021, The Authors. Published by Elsevier Inc. and Fass Inc. on behalf of the American Dairy Science Association ${ }^{\circledR}$. This is an open access article under the CC BY-NC-ND license (http://creativecommons.org/licenses/by-nc-nd/4.0/).

\title{
Chronic prepartum light-dark phase shifts in cattle disrupt circadian clocks, decrease insulin sensitivity and mammary development, and are associated with lower milk yield through 60 days postpartum
}

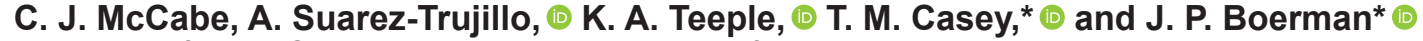 \\ Department of Animal Sciences, Purdue University, West Lafayette, IN 47907
}

\section{ABSTRACT}

Circadian and metabolic systems are interlocked and reciprocally regulated. To determine if the circadian system regulates glucose homeostasis and mammary development, the function of the circadian system was disrupted by exposing cattle to chronic light-dark cycle phase shifts from 5 wk before expected calving (BEC) to parturition. Multiparous Holstein cows were exposed to $16 \mathrm{~h}$ of light and $8 \mathrm{~h}$ of dark $(\mathrm{CON}, \mathrm{n}=8)$ or phase shifting (PS, $\mathrm{n}=8$ ) the light cycle 6 h every $3 \mathrm{~d}$ beginning 35 d BEC. After calving, both treatments were exposed to CON lighting. Mammary biopsies were taken at $21 \mathrm{~d}$ BEC and $21 \mathrm{~d}$ in milk (DIM), and histological analysis indicated PS treatment decreased the ratio of lumen to alveolar area and percentage of proliferating epithelial cells in the prepartum period. Intravenous glucose tolerance test was performed at $14 \mathrm{~d}$ BEC and 7 DIM by administering $50 \%$ dextrose. Blood glucose, $\beta$-hydroxybutyrate, insulin, and nonesterified fatty acids were consequently measured over $3 \mathrm{~h}$. At $14 \mathrm{~d}$ BEC no treatment differences were observed in baseline glucose or insulin. Treatment had no effect on blood glucose or glucose area under the curve at $14 \mathrm{~d}$ BEC and 7 DIM. Insulin area under the curve was higher in PS versus CON at $14 \mathrm{~d}$ BEC and 7 DIM. The PS cows produced less milk than CON cows through 60 DIM (40.3 vs. $42.6 \mathrm{~kg} / \mathrm{d}$ ). Exposure to chronic light-dark PS in late gestation decreased mammary development and increased insulin resistance in periparturient cows, which may have caused subsequent lower milk yield.

Key words: circadian disruption, insulin sensitivity, mammary development

Received July 8, 2020

Accepted September 17, 2020.

*Corresponding authors: theresa-casey@purdue.edu and jboerma@ purdue.edu

\section{INTRODUCTION}

The most metabolically demanding time for dairy cattle is the transition from late gestation to early lactation. During this time, major shifts in nutrient partitioning occur to support fetal growth in late gestation and then to support the metabolic demands of milk synthesis in early lactation. Physiological changes in response to the increased metabolic demands are reflected in changes in plasma metabolite and hormone levels, which are marked by decreased levels of glucose and insulin, and increased nonesterified fatty acids (NEFA) and BHB (Bauman and Currie, 1980). To facilitate this transition, cows undergo natural insulin resistance by reducing insulin sensitivity in the peripheral tissues to spare glucose for late-term fetal growth and milk production (Bell et al., 2000; De Koster and Opsomer, 2013). To maintain health, cows must sustain homeostasis while coordinating changes in metabolism in almost every tissue of the body during late pregnancy and early lactation. Minimization of the number of disturbances through the transition period is a strong predictor of the health and production performance of a dairy cow lactation (Duffield et al., 2009).

The transition period commonly overlaps with the 45to 60 -d nonlactating dry period in which the mammary gland undergoes significant remodeling to replenish mammary parenchymal tissue (Hurley, 1989; Capuco et al., 1997; DeVries et al., 2010). The first half of the dry period is marked by high levels of programmed cell death and extracellular matrix remodeling. The second half of the dry period is characterized by high levels of proliferation of mammary epithelial cells (MEC) in the glands in preparation for the ensuing lactation (Zhao et al., 2019). Mammary remodeling during the dry period is critical as the number and metabolic activity of MEC directly corresponds with the cow's milk production capacity (Knight, 2000), and dry period management and environmental factors, such as photoperiod and heat stress, are known to affect mammary development during this time (Collier et al., 2006; Dahl, 2008; Mabjeesh et al., 2013). 
The circadian timing system (CTS) is a homeostatic system that functions to coordinate the timing of internal physiological processes across the body through the generation of 24-h rhythms of behavior and physiology (Nakagawa and Okumura, 2010). In mammals, the CTS is regulated hierarchically, such that the master clock in the suprachiasmatic nuclei of the hypothalamus integrates temporal cues from the environment and physiological systems, and in turn, sends out neural and hormonal signals to synchronize the timing of peripheral clocks across the body (Mohawk et al., 2012). Circadian rhythms enable animals to anticipate and prepare physiology for precise and regular environmental changes, with the $24 \mathrm{~h}$ light-dark cycle serving as a primary environmental cue (Stenvers et al., 2019).

Disruptions in the normal timing of temporal cues in the animal's environment can disrupt the CTS (Reppert and Weaver, 2002). Since circadian clocks and metabolic systems are interlocked and reciprocally regulated, disruptions of the CTS disrupt metabolic systems and can affect health (Gangwisch, 2009; Buxton et al., 2012). Therefore, it is plausible that management factors that cause chronodisruption may also affect the metabolic health of cattle during the transition period, which is supported by studies in other species. For example, epidemiological studies of pregnant women reported that working nights or rotating shift work, which disrupt circadian clocks, was associated with an increased risk of preterm delivery, intrauterine growth restriction, and preeclampsia (Valenzuela et al., 2015). Sleep disruption, which also disrupts circadian clocks, during pregnancy was associated with increased risk of hyperglycemia and gestational diabetes mellitus (Herring et al., 2014; Facco et al., 2017). Studies conducted in sheep during pregnancy found that exposure to chronic light-dark phase shifts similar to rotating shift work light exposure increased the likelihood of a delayed lambing and reduced lamb weights (Gatford et al., 2019). The same study demonstrated ewes exposed to chronic shift work model had decreased insulin sensitivity and increased peak glucose in response to a glucose tolerance test in single lamb dams. However, there was no effect on glucose tolerance or insulin sensitivity in dams that lambed twins. Conversely, a crossover design study in nonpregnant, nonlactating ewes decreased circulating glucose levels with no difference in insulin sensitivity under a glucose tolerance test with a rapid alternating timing of the light cycle (Varcoe et al., 2014).

Genetic studies conducted to understand the role of circadian clocks in reproduction found the Clock $\Delta 19$ line of mice, which have a germline mutation resulting in loss of rhythmicity and lower expression of CLOCK regulated gene expression, found the mutation decreased lactation competence (Kennaway et al.,2004;
Dolatshad et al., 2006; Hoshino et al., 2006). Clock 119 mice exhibit altered glucose homeostasis and impaired mammary development in late pregnancy (Turek et al., 2005; Casey et al., 2016). Sleep disruption during pregnancy in women was associated with hyperglycemia and delayed onset of lactogenesis (Casey et al., 2019). A crossover study design of dairy cattle found that exposure to chronic light-dark phase shifts during an established lactation decreased milk yield (Casey et al., 2014). On the other hand, late pregnant nonlactating dry cows exposed to chronic light-dark phase shifts over the last 5 wk of gestation had reduced plasma glucose concentrations and yielded a greater amount of milk during the following 2 mo of lactation compared with a group under a consistent timing of light (Suarez-Trujillo et al., 2020). Restricting feeding time to normal times of rests disrupts the CTS. A crossover design study found cattle restricted to feed availability during dark hours produced more milk as compared with periods when feed was available during periods of light exposure with no differences in DMI (Salfer and Harvatine, 2020). Thus, alterations in the CTS on glucose metabolism and milk production metrics in ruminants have shown mixed results.

Based on these previous findings, we hypothesized animals with a disrupted CTS would have reduced insulin sensitivity in response to a glucose challenge, compromised mammary development, and reduced milk yield in the subsequent lactation. Therefore, our objective was to measure the effect of disrupting the CTS by exposing late gestation, nonlactating dry cows to chronic light-dark phase shifts on insulin sensitivity, mammary development, and milk yield through 60 DIM.

\section{MATERIALS AND METHODS}

\section{Animal Management and Experimental Design}

The experiment was performed from February to June 2019 in the tiestall barn at the Purdue University Animal Sciences Research and Education Center dairy. All procedures described were approved by Institutional Animal Care and Use Committee protocol \#1701001523 before beginning the study. Sixteen multiparous Holstein cows were enrolled into one of 2 treatments, control (CON) or phase shift (PS), and blocked by lactation number $(2.88 \pm 0.64$ vs. $2.88 \pm 0.64)$ and previous lactation yield $(12,087 \pm 2,486$ vs. $12,467 \pm$ $2,407 \mathrm{~kg}$ ). Animals enrolled in a previous study $(\mathrm{n}=6$ in Suarez-Trujillo et al., 2020) conducted the previous year were enrolled to the opposite treatment $(\mathrm{n}=3$ / treatment). Cows were dried off at $60 \mathrm{~d}$ before expected calving (BEC) and moved to the experimental barn at 
A)

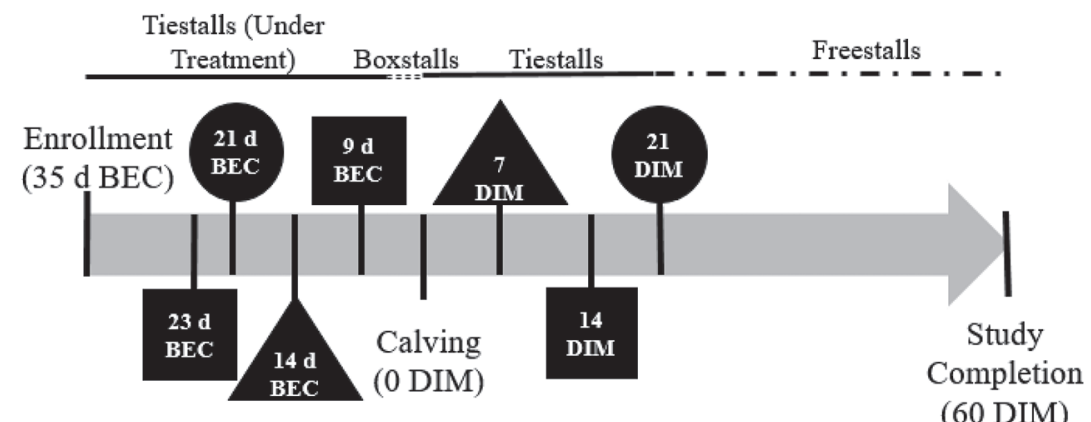

B)
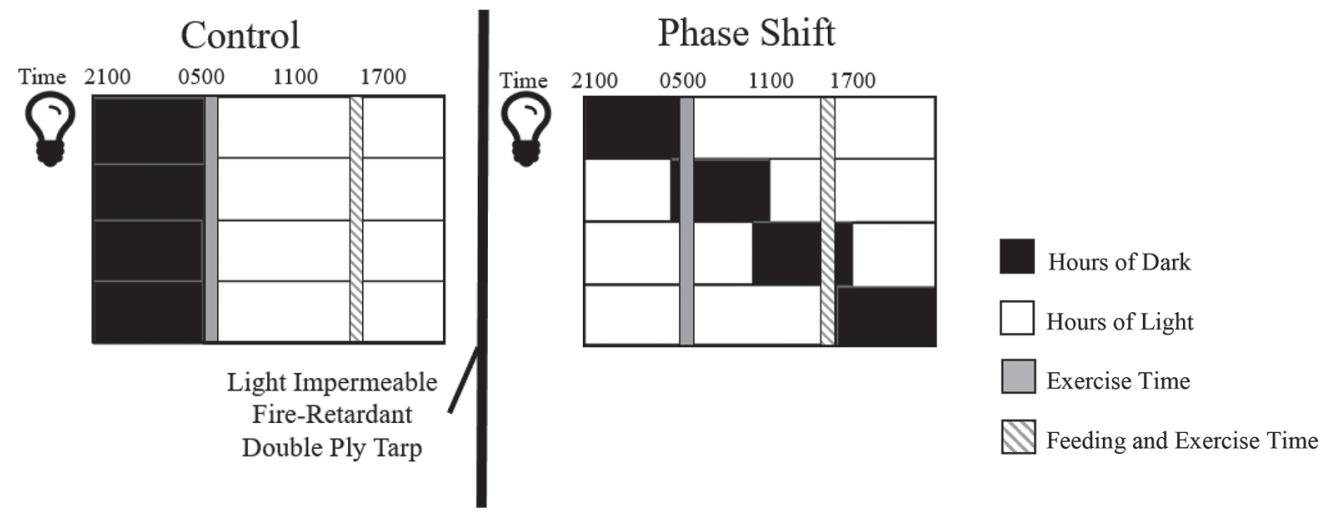

Figure 1. Schematic diagram of the study design. Sixteen multiparous Holstein cows were blocked to either a control (CON) or phase shift (PS) treatment at $35 \mathrm{~d}$ before expected calving (BEC). (A) At study enrollment cows were housed in tiestalls under lighting treatment as seen in panel B. Directly before calving at approximately $3 \mathrm{~d}$ BEC cows were moved to boxstalls where they experienced CON lighting. Cows were moved back to tiestalls after calving through 21 DIM when they were moved to the freestall barn for the remainder of the study. Cows received

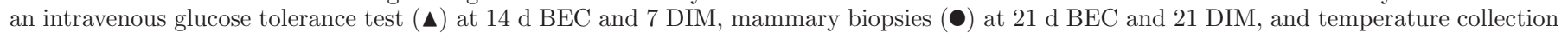
over $48 \mathrm{~h}$ to assess circadian rhythm (ם) at $23 \mathrm{~d}$ BEC, $9 \mathrm{~d}$ BEC, and 14 DIM. (B) The cows were housed in the same barn under treatment while they were separated by a double-ply light-impermeable tarp. The CON animals received a consistent timing of $16 \mathrm{~h}$ of light (0500-2100 h), $8 \mathrm{~h}$ of dark $(2100-0500 \mathrm{~h}$ ) from $35 \mathrm{~d}$ BEC until $3 \mathrm{~d}$ BEC. The PS cows received a 6 -h forward shifting timing of the start of the photophase every $3 \mathrm{~d}$ for $16 \mathrm{~h}$ of light (0500-2100 h; 1100-0300 h) and $8 \mathrm{~h}$ of dark (2100-0500 h; 0300-1100 h). Feeding and exercise time was held constant for all animals at $1600 \mathrm{~h}$ when animals were under treatment.

35 d BEC. From 35 d BEC to calving, all cows received $16 \mathrm{~h}$ of light and $8 \mathrm{~h}$ of darkness. Light phase for CON cows was from 0500 to $2100 \mathrm{~h}$, and dark phase was from 2100 to 0500 h daily (Figure 1). For the PS group the timing of the start of a 16- to 8-h light-dark cycle phase was shifted forward by 6 h every 3 d. Exposure to lightdark phase shifts was from 35 d BEC to approximately $3 \mathrm{~d}$ BEC when all cattle were moved to boxstalls in the maternity barn for calving. From 3 d BEC to 60 DIM all animals were on the CON light-dark schedule.

As detailed by Suarez-Trujillo et al. (2020), in the prepartum period, all animals were housed in the same experimental tiestall barn, which was partitioned to separate treatments with floor to ceiling draping of 2 layers of fire-retardant tarps (Tarps Plus, Abadak Inc., Georgetown, TX). Outside sources of light were blocked by covering windows with black plastic and caulking was used around doors to block natural light. The light source consisted of bright white light-emitting diode (LED) lights (Smart Electrician $5000 \mathrm{~lm} 46$ $\times 6$ LED Tread Plate Shop Light, Menards Inc., Eau Claire, WI), that were positioned for $150 \mathrm{~lx}$ of light to be present at eye level for all cows. The lights were synchronized to turn on at the aforementioned times using an automatic timer.

\section{Circadian Rhythm Assessment}

At 23 and $9 \mathrm{~d}$ BEC and 14 DIM vaginal temperature was measured in each cow every $30 \mathrm{~min}$ to determine internal temperature circadian rhythm over a 48-h period as described by Burdick et al. (2012). Briefly, internal temperature loggers (iButton DS1921H-F5\#, iButtonLink Technology, Baulkham Hills, Australia) were secured onto the plastic skeleton of a controlled internal drug release device (EAZI-Breed CIDR Cattle Insert, Zoetis Inc., Parsippany, Troy Hills, NJ) and inserted into the vagina. Loggers were programmed to begin temperature recordings at $0430 \mathrm{~h}$ and continued every $30 \mathrm{~min}$ for $48 \mathrm{~h}$. 
DMI

Feed ingredient samples were collected every 2 wk and analyzed for nutrient composition. Samples were dried at $60^{\circ} \mathrm{C}$ for $48 \mathrm{~h}$ and ground through a $1 \mathrm{~mm}$ mill (Retsch GmbH, Haan, Germany). Feed samples were measured for NDF and ADF (Van Soest et al., 1991; Ankom, Macedon, NY), whereas percent ash content was determined by contents remaining after a 24-h oven cycle at $600^{\circ} \mathrm{C}$. Crude protein was determined on a pure nitrogen basis by combustion analysis (Leco, St. Joseph, MI) and then multiplied by 6.25 to determine $\mathrm{CP}$ percentage.

Animals were offered ad libitum feed daily at 1600 $\mathrm{h}$ by dispersing feed at $110 \%$ of the previous day's intake. Daily DMI of individual cows was calculated by weighing the feed offered and subtracting refusals from 35 d BEC until 21 DIM when cows were moved to the freestall barn. The ingredient composition of the delivered as-fed diet was determined via TMR Tracker (Topcon Agriculture Group; Fort Atkinson, WI). To calculate diet DM, each individual feedstuff was multiplied by their respective percent DM. Feed intake was then multiplied by the ration percent DM to determine DMI. Cows were fed a prefresh diet $(52.9 \%$ DM, $15.9 \%$ CP, $37.5 \%$ NDF, $24.4 \%$ ADF, and $5.7 \%$ ash; Table 1) from enrollment at $35 \mathrm{~d}$ BEC until calving. Once calving occurred, cattle were fed a lactating diet $(51.8 \%$ $\mathrm{DM}, 15.3 \% \mathrm{CP}, 27.2 \% \mathrm{NDF}, 18.4 \% \mathrm{ADF}$, and $5.1 \%$ ash) through 60 DIM.

\section{Milk Sampling and Analysis}

Animals were milked twice daily at 0500 and $1600 \mathrm{~h}$. A homogeneous milk sample was collected in the parlor from both milking time points at $7,14,21,30$, and 60 DIM. Milk samples were sent to Dairy One (Ithaca, NY) for analysis of protein, fat, SCC, MUN, and TS using infrared technology (MilkoScan 7 RM, Foss, Hillerød, Denmark). Component yield for the day was calculated by multiplying the component percentage by the milking weight as recorded by the Afifarm Software (Afimilk USA Inc., Fitchburg, WI) and then summing the yield from the morning and afternoon milk weights. Component percentages were determined by dividing the component yield by the total milk yield for that test day. Somatic cell count data were transformed by a $\log _{10}$ scale and subsequently analyzed.

\section{Intravenous Glucose Tolerance Test}

At approximately $14 \mathrm{~d}$ BEC and 7 DIM all cows underwent an intravenous glucose tolerance test (IVGTT). The $14 \mathrm{~d}$ BEC and 7 DIM time points were selected to
Table 1. Study diet ingredients and nutrient composition for prefresh and lactating diets

\begin{tabular}{|c|c|c|}
\hline Item & Prefresh & Lactating \\
\hline \multicolumn{3}{|l|}{ Ingredient $(\mathrm{g} / 100 \mathrm{~g}$ of $\operatorname{diet} \mathrm{DM})$} \\
\hline Corn silage & 32.18 & 29.84 \\
\hline Mixed mostly legume silage & 5.31 & 8.35 \\
\hline Straw & 15.30 & 6.93 \\
\hline Alfalfa hay & - & 9.29 \\
\hline Cottonseed hulls & 7.18 & - \\
\hline Soybean meal & 6.61 & 5.82 \\
\hline Dry ground corn & 10.46 & 9.59 \\
\hline High-moisture corn & - & 14.81 \\
\hline AA blend ${ }^{1}$ & 9.48 & 5.31 \\
\hline Prefresh supplement $^{2}$ & 11.28 & - \\
\hline Lactation supplement $^{3}$ & - & 3.74 \\
\hline QLF $6343^{4}$ & 2.19 & 4.12 \\
\hline Palmit $80^{5}$ & - & 2.19 \\
\hline Water (\% as fed) & 9.1 & 11.0 \\
\hline \multicolumn{3}{|l|}{ Nutrient composition (\%) } \\
\hline DM & 52.9 & 51.8 \\
\hline $\mathrm{CP}$ & 15.9 & 15.3 \\
\hline $\mathrm{NDF}$ & 37.5 & 27.2 \\
\hline $\mathrm{ADF}$ & 24.4 & 18.4 \\
\hline Ash & 5.7 & 5.1 \\
\hline
\end{tabular}

${ }^{1}$ AA blend included $84.24 \%$ blood meal, $6.39 \%$ Smartamine (Adisseo, Alpharetta, GA), 6.28\% Biocycle Plus (Agrarian Solutions, Middlebury, IN), and 3.09\% AjiPro-L (Ajinomoto Animal Nutrition, Chicago, IL). ${ }^{2}$ Prefresh supplement included $63.12 \%$ Biochlor (Arm \& Hammer Animal Nutrition, Princeton, NJ), $10.55 \%$ calcium carbonate, $7.51 \%$ Megalac (Volac Wilmar, Orwell, UK), 3.67\% magnesium oxide, $3.49 \%$ Diamond V XP (Diamond V, Cedar Rapids, IA), $2.40 \%$ monocalcium phosphate, $2.24 \%$ magnesium sulfate, $1.93 \%$ white salt, $1.77 \%$ vitamin E, $1.60 \%$ calcium sulfate dihydrate, $1.55 \%$ mineral premix, and less than 1\% Rumensin (Elanco Animal Health, Greenfield, IN) and vitamin $\mathrm{A}$

${ }^{3}$ Lactating premix included $27.48 \%$ calcium carbonate, $21.03 \%$ sodium bicarbonate, $10.57 \%$ white salt, $8.46 \%$ calcium phosphate, $8.34 \%$ $\mathrm{DCAD}^{+}$(Arm \& Hammer Animal Nutrition), $5.13 \%$ magnesium oxide, $4.98 \%$ Diamond V XP (Diamond V), $4.65 \%$ calcium sulfate dihydrate, $4.58 \%$ fat yellow grease, $2.64 \%$ mineral premix, less than $2 \%$ ETX5 (Feedworks USA, Cincinnati, OH), and less than $1 \%$ vitamin E and Rumensin (Elanco Animal Health).

${ }^{4}$ Quality Liquid Feeds, Dodgeville, WI.

${ }^{5} \mathrm{ADM}$ Animal Nutrition, Quincy, IL.

ensure that all cattle would have a test performed while under treatment and to assess cattle insulin sensitivity during the period of expected greatest insulin resistance, respectively (De Koster and Opsomer, 2013). One CON cow did not complete the IVGTT at the $14 \mathrm{~d}$ BEC time point, due to complications with catheterization. Animals were weighed either the morning before or the morning of test date following the morning milking to the nearest half kilogram. Without the use of local anesthetic, an indwelling jugular catheter was inserted in either the right or left jugular vein the morning of IVGTT (0600 to $0800 \mathrm{~h}$ ). At $1100 \mathrm{~h}$, feed was removed from all animals for $1 \mathrm{~h}$ before dextrose administration. Feed was not made available at any time throughout the test, but water was available at all times. Baseline blood samples were collected at $15(\mathrm{t}=-15)$ and $5(\mathrm{t}$ $=-5)$ min before dextrose administration via blood 
sample through catheter lines using a $12-\mathrm{mL}$ syringe (Covidien, Dublin, Ireland). A dose of $250 \mathrm{mg} / \mathrm{kg} \mathrm{BW}$ of glucose was administered intravenously via $60-\mathrm{mL}$ syringes in the form of a $50 \%$ dextrose solution (Vet One, Boise, ID), at time point $0(\mathrm{t}=0)$. The dispensing time to infuse the entire dextrose dose ranged from 3 to $13 \mathrm{~min}$, with a mean of $7.5 \pm 2.2 \mathrm{~min}$. Immediately following administration of dextrose, catheter lines were flushed with $20 \mathrm{~mL}$ of saline, which was followed by blood sample collection from the same catheter. Subsequent blood samples were taken from the jugular catheters at time $5,10,15,20,30,40,50,60,75,90$, 120,150 , and $180 \mathrm{~min}$ relative to the completion of the glucose infusion.

\section{Blood Metabolite Analysis}

An aliquot of whole blood was used to measure glucose and BHB concentrations using the Centrivet GK Blood Glucose \& Ketone Monitoring System (Acon Laboratories, San Diego, CA). The remaining $10 \mathrm{~mL}$ of whole blood was transferred into a 10-mL EDTA tube (Becton Dickinson, Franklin Lakes, NJ) and centrifuged at $4,000 \times g$ for $15 \mathrm{~min}$ at $4^{\circ} \mathrm{C}$. Three aliquots of plasma were frozen in $-20^{\circ} \mathrm{C}$ until further analysis.

Plasma concentrations of insulin and NEFA were analyzed in duplicate using bovine insulin (ALPCO, Salem, NH) and NEFA kits (WAKO, Mountain View, CA). Intraplate coefficients of variation were $1.72 \%$ and $3.93 \%$ for NEFA and insulin, respectively. Interplate coefficients of variation were $8.00 \%$ and $15.74 \%$ for NEFA and insulin, respectively.

The area under the curve (AUC) was calculated for glucose and insulin concentrations from 0 to $180 \mathrm{~min}$ using the trapezoidal rule (Pires et al., 2007). Insulin increment was calculated by subtracting baseline insulin concentration from the peak insulin concentration. Insulin clearance rate was calculated as the slope between the peak insulin concentration and insulin concentration at $60 \mathrm{~min}$ postglucose administration. Glucose clearance rate was calculated using the formula

$$
\text { glucose clearance rate }=\frac{\ln \left([\text { glucose }]_{0}\right)-\ln \left([\text { glucose }]_{60}\right)}{60},
$$

and the time to half-maximal glucose concentration was calculated using the equation

$$
\frac{\ln (2)}{\ln (\text { glucose clearance rate })}
$$

as detailed in Kerestes et al. (2009). To calculate a cow's revised quantitative insulin sensitivity check in- dex (RQUICKI; Holtenius and Holtenius, 2007), the following formula was used:

$$
\text { RQUICKI }=\frac{1}{\log (\text { glucose })+\log (\text { insulin })+\log (\text { NEFA })}
$$

The addition of baseline BHB was used to determine RQUICKI_BHB as detailed in Balogh et al. (2008) with

$$
\begin{gathered}
\text { RQUICKI_BHB }= \\
\frac{1}{\log (\text { glucose })+\log (\text { insulin })+\log (\text { NEFA })+\log (\text { BHB })} .
\end{gathered}
$$

The greater the RQUCIKI and RQUICKI_BHB scores the greater the baseline insulin sensitivity.

\section{Mammary Biopsy}

At $21 \mathrm{~d}$ BEC and 21 DIM, mammary gland biopsies were taken from the left-rear and right-rear quarter, respectively, as described by De Vries et al. (2010). Before biopsy, cows were restrained in a squeeze chute and sedated using xylazine via intravenous coccygeal vein injection (Rompun, Bayer HealthCare LLC, Animal Health Division, Shawnee, KS). The biopsy site was shaved and thoroughly cleaned with diluted betadine and $70 \%$ ethanol. Skin was locally anesthetized by injecting $10 \mathrm{~mL}$ of $2 \%$ lidocaine $\mathrm{HCl}$ subcutaneously (Vet One). An incision was made through the skin using a scalpel to expose underlying mammary tissue. Approximately $1 \mathrm{~g}$ of tissue was collected using a stainless-steel, retractable biopsy tool (AgResearch, Christchurch, New Zealand). Tissue was rinsed with sterile PBS and divided into 4 sections. Tissue preserved for histology was placed in 10\% buffered formalin and stored at room temperature. The remaining pieces were flash frozen in liquid nitrogen and stored at $-80^{\circ} \mathrm{C}$.

\section{Histological Analysis of Mammary Morphology and Cell Proliferation Index}

Purdue University Histology Research Laboratory prepared and stained mammary tissue sections with hematoxylin and eosin $(\mathbf{H} \& \mathbf{E})$ and immunostained for KI67 expression. Briefly, after fixation in 10\% neutral buffered formalin for $24 \mathrm{~h}$, tissues were placed in a Sakura Tissue-Tek VIP6 tissue processor (Sakura Finetek USA Inc., Torrance, CA) for dehydration through graded ethanols, clearing in xylene, and infiltration with Leica Paraplast Plus paraffin (Leica Microsystems Inc., Buffalo Grove, IL). Using a Thermo HM355S mi- 
crotome (Thermo Fisher Scientific, Waltham, MA), 4 $\mu M$ sections were cut and mounted on charged slides and dried for 30 to $60 \mathrm{~min}$ at $60^{\circ} \mathrm{C}$. After drying, all slides were deparaffinized through 3 changes of xylene and rehydrated through graded ethanols to water in a Leica Autostainer XL (Leica Microsystems Inc., Buffalo Grove, IL).

Using the Leica Autostainer XL, slides were stained in Gill's II hematoxylin, blued, and counter-stained in an eosin/phloxine B mixture (H\&E stained section). Finally, slides were dehydrated, cleared in xylene, and coverslips were placed in a toluene-based mounting medium (Leica MM24).

For immunostaining with KI67, deparaffinized tissues were subject to antigen retrieval by incubating in a Tris/EDTA (pH 9.0) solution in a decloaking chamber (BioCare Medical, Pacheco, CA) at a temperature of $95^{\circ} \mathrm{C}$ for $20 \mathrm{~min}$. Slides were cooled for $20 \mathrm{~min}$ at room temperature and transferred to Tris buffer with Tween 20 detergent (TBST), and for the remainder of the protocol, staining was carried out at room temperature using an Intellipath stainer (BioCare Medical). Slides were incubated with $3 \%$ hydrogen peroxide in water for $5 \mathrm{~min}$, rinsed with TBST, and incubated in 2.5\% normal goat serum (Vector Labs, Burlingame, CA) for $20 \mathrm{~min}$. Excess reagent was blown off, and KI67 (275R-16, Cell Marque, Rocklin, CA) was applied at a dilution of $1: 100(0.364 \mu \mathrm{g} / \mathrm{mL})$ for $30 \mathrm{~min}$. The negative control slide was stained with rabbit $\operatorname{IgG}$ (I-1000, Vector Labs) at a concentration of 1:5,000 $(1 \mu \mathrm{g} / \mathrm{mL})$ for $30 \mathrm{~min}$. Slides were rinsed twice in TBST and a goat anti-rabbit secondary antibody (MP-7451, Vector Labs) was applied for $30 \mathrm{~min}$. Slides were rinsed twice in TBST and Vector ImmPACT DAB (SK-4105, Vector Labs) was applied for $5 \mathrm{~min}$. Slides were rinsed in water and transferred to a Leica Autostainer XL for hematoxylin counter-stain, dehydration, and placement of coverslips.

ImagePro Plus 5.1 (Media Cybernetics Inc., Rockville, MD) was used to capture and analyze images. Mammary biopsies were taken from all cows at both time points, but good quality parenchymal tissue was only available from 6 cows per treatment at the prepartum time point. Five H\&E stained images were captured per biopsy per cow $(\mathrm{n}=6 /$ treatment prepartum; $\mathrm{n}=8 /$ treatment postpartum) at $40 \times$ (Nikon Eclipse 50i, Nikon Inc., Melville, NY; Evolution MP, Media Cybernetics Inc.). The H\&E stained tissue was used to measure alveolar area and lumen area. The "Draw/ Merge: Trace" tool was used to trace around the entire alveolus and area calculated using ImagePro (Figure $2 \mathrm{~A})$; then, the tool was used to trace around the lumen (Figure 2B) and area was calculated. Ratio was calculated by dividing the luminal area by the alveolar area.

Five KI67 immunostained images were captured per biopsy per cow at $200 \times$. The proliferation index for MEC and intralobular stromal cells was determined by counting the number of proliferating (cells that were stained with KI67) and nonproliferating cells using the count tool.

\section{Statistical Analysis}

A priori power analysis was performed using data from studies on the effect of different photoperiod length exposures during the dry period on epithelial cell proliferation at 3 wk BEC. Using 6 animals per group the power of the study was found to be $100 \%$ if there was a 3-fold difference in cell proliferation rate, with a standard deviation of 0.5 -fold (Wall et al., 2005). If the difference dropped to 2 -fold, the calculated power was $96 \%$.
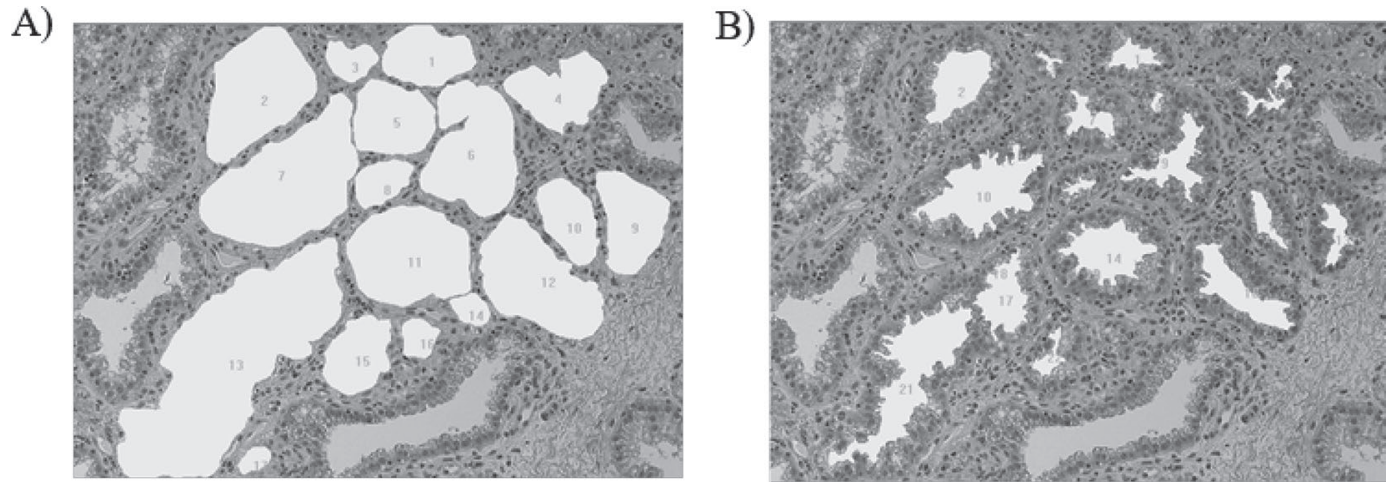

Figure 2. Representative images of histological mammary tissue biopsies used to quantify lumen:aleveolar ratio, percent epithelial proliferation, and percent stromal proliferation. (A) Hematoxylin and eosin (H\&E) stained cross section of mammary tissue in the DIM state. The complete alveoli in the image are drawn around to record their collective area. (B) H\&E staining cross section of the same mammary tissue sample in the DIM state. The lumen of the complete alveoli in the image are drawn around to record their collective area. 
Vaginal temperature data were analyzed for fit to a 24-h cosine curve using the cosinor package in $\mathrm{R}$ (RStudio 1.1.453, Boston, MA). MESOR, amplitude, and acrophase were program outputs and calculated for each animal at the 3 study time points of 23 and 9 d BEC and 14 DIM. Temperature data, proliferation indexes, lumen to alveolar ratio, milk yield, and DMI were analyzed using the MIXED Procedure of SAS 9.4 (SAS Institute Inc., Cary, NC). The following model was used:

$$
\mathrm{Y}_{\mathrm{ijkl}}=\mu+\mathrm{T}_{\mathrm{i}}+\mathrm{P}_{\mathrm{j}}+\mathrm{S}_{\mathrm{k}}+\mathrm{C}(\mathrm{T})_{\mathrm{il}}+\mathrm{e}_{\mathrm{ijkl}},
$$

where $Y_{i j k l}$ is the dependent variable, $\mu$ is the overall mean, $T_{i}$ is the fixed effect of treatment $(i=C O N$ or PS), $\mathrm{P}_{\mathrm{j}}$ is the fixed effect of time point (temperature data $\mathrm{j}=23 \mathrm{~d}$ BEC, $9 \mathrm{~d}$ BEC, or 14 DIM; MEC proliferation and lumen to alveolar ratio $\mathrm{j}=21 \mathrm{~d}$ BEC or 21 DIM; and milk yield $\mathrm{j}=1-60$ DIM; DMI $\mathrm{j}=35 \mathrm{~d}$ BEC21 DIM), $S_{k}$ is the fixed effect of physiological state [k $=$ prepartum $(\mathrm{BEC})$ or postpartum $(\mathrm{DIM})] ; \mathrm{C}(\mathrm{T})_{\mathrm{il}}$ is the random effect of cow nested within treatment, and $\mathrm{e}_{\mathrm{ijk} \mathrm{l}}$ is the residual error term. Due to the treatment only being applied during the prepartum period, preand postpartum time points were run independently to assess treatment effects during the treatment period as well as any potential carryover effects into lactation. For temperature data, if physiological state was found to be significant, Tukey's honestly significant difference test was used to assess time point differences between days treatments. Additionally, to assess the effect of physiological state, both prepartum and postpartum time points were included in the model.

The IVGTT glucose, BHB, NEFA, and insulin data were analyzed using the MIXED Procedure of SAS 9.4. The following model was used:

$$
\mathrm{Y}_{\mathrm{ijk}}=\mu+\mathrm{T}_{\mathrm{i}}+\mathrm{P}_{\mathrm{j}}+\mathrm{TP}_{\mathrm{ij}}+\mathrm{C}(\mathrm{T})_{\mathrm{ik}}+\mathrm{bl}+\mathrm{e}_{\mathrm{ijk}},
$$

where $Y_{i j k}$ is the dependent variable, $\mu$ is the overall mean, $\mathrm{T}_{\mathrm{i}}$ is the fixed effect of treatment $(\mathrm{i}=\mathrm{CON}$ or PS), $\mathrm{P}_{\mathrm{j}}$ is the fixed effect of time point relative to glucose administration ( $\mathrm{j}=0$ to $180 \mathrm{~min}), \mathrm{TP}_{\mathrm{ij}}$ is the interaction effect of treatment $\times$ time point, $\mathrm{C}(\mathrm{T})_{\mathrm{ik}}$ is the random effect of cow nested within treatment $(\mathrm{k}=$ 1 to 16 th cow), bl is the hormone or metabolite baseline covariate as average of $\mathrm{t}=-15$ and -5 min relative to glucose infusion, and $e_{i j k}$ is the residual error term.

Data were screened for influential outlier points where Cook's $D$ values were $\geq 0.5$; data points above this cutoff were removed ( $\mathrm{n} \leq 3$ per analysis). Data were considered significant at $P \leq 0.05$ and trends were indicated if $P \leq 0.10$ to $>0.05$. If there was a significant treatment or treatment $\times$ time point effect, the SLICE method was used to determine differences between treatments at different time points.

\section{RESULTS}

\section{Temperature Circadian Rhythm Data}

The $\mathrm{R}^{2}$ and $P$-value variables calculated from cosine fit analysis reflect the relative fit of the data to a cosine curve within a 24 -h period. Across all time points, temperature rhythms in both treatments fit 24-h rhythms (all $P<0.05$; Table 2). There was no significant difference in $\mathrm{R}^{2}$ between treatments at $23 \mathrm{~d}$ BEC; however, at $9 \mathrm{~d}$ BEC temperature data for CON cows fit a $24-\mathrm{h}$ cosine curve better than PS cows $\left(P<0.05 ; \mathrm{R}^{2}, 0.48\right.$ vs. 0.23$)$. Treatment had no effect on $\mathrm{R}^{2}$ or $P$-value at 14 DIM $(P>0.05)$. All cows' temperature data had a stronger fit to a cosine curve at 23 and $9 \mathrm{~d}$ BEC compared with 14 DIM ( $P<0.05 ; 0.40$ vs. 0.35 vs. 0.20 ).

Circadian rhythm temperature amplitude is a relative measure of circadian rhythm strength and was affected by treatment and physiological time point. Although there was no difference in amplitude between treatments at $23 \mathrm{~d}$ BEC $(P>0.05)$, PS cows had lower rhythm amplitudes than CON at $9 \mathrm{~d}$ BEC $(P<0.05)$. At 14 DIM mean amplitude of core body temperature was not different between treatments. Temperature amplitude did not differ between the 3 physiological time points $(P>0.05)$.

Acrophase, or the time of day the rhythm peaks, was not affected by physiological state or treatment. MESOR, the rhythm-adjusted mean, and the AUC of body temperature were not affected at any time point by treatment. Between 23 to $9 \mathrm{~d}$ BEC MESOR and AUC increased $\left(P<0.05 ; 39.04\right.$ vs. $39.30^{\circ} \mathrm{C} ; 1,894$ vs. $1,906^{\circ} \mathrm{C} / 48 \mathrm{~h}$ ), but there was no difference in MESOR and AUC between $9 \mathrm{~d}$ BEC and 14 DIM.

\section{Intravenous Glucose Tolerance Tests}

At $14 \mathrm{~d}$ BEC there was no difference in baseline glucose, BHB, insulin, or NEFA between treatments (Table 3), and no difference between baseline insulin sensitivity, as indicated by RQUICKI. However, when BHB was added into the calculation (RQUICKI_BHB), PS cows had lower baseline insulin sensitivity at $14 \mathrm{~d}$ BEC compared with CON $(P<0.05 ; 0.55$ vs. 0.66$)$. At 7 DIM, PS cows had higher baseline glucose $(P=0.05$; 67.63 vs. $61.50 \mathrm{mg} / \mathrm{dL})$, lower BHB $(P<0.05,1.49$ vs. $0.97 \mathrm{mmol} / \mathrm{L})$, and higher NEFA $(P<0.01,0.71$ vs. $0.43 \mathrm{mmol} / \mathrm{L}$ ) concentrations, compared with CON. No difference was observed in baseline insulin concentrations between the treatments, and no significant dif- 
Table 2. Cosine fit analysis of core body temperature $\left({ }^{\circ} \mathrm{C}\right)$ at 23 and $9 \mathrm{~d}$ before expected calving (BEC) and 14 DIM in control (CON; $\mathrm{n}=8$ ) and phase-shifted (PS; $\mathrm{n}=8) \mathrm{cows}^{1}$

\begin{tabular}{|c|c|c|c|c|}
\hline \multirow[b]{2}{*}{ Item } & \multicolumn{4}{|c|}{$23 \mathrm{~d}$ BEC } \\
\hline & $\mathrm{CON}$ & PS & SEM & $P$-value ${ }^{2}$ \\
\hline $\operatorname{MESOR}\left({ }^{\circ} \mathrm{C}\right)$ & 38.99 & 39.09 & 0.08 & 0.37 \\
\hline Amplitude $\left({ }^{3} \mathrm{C}\right)$ & 0.20 & 0.15 & 0.03 & 0.18 \\
\hline Acrophase $^{4}(\mathrm{~h})$ & 2142 & 0023 & 86 & 0.19 \\
\hline $\mathrm{R}^{25}$ & 0.47 & 0.33 & 0.06 & 0.13 \\
\hline$P$-value ${ }^{6}$ & $<0.05$ & $<0.05$ & 0.01 & 0.37 \\
\hline \multirow[t]{3}{*}{$\mathrm{AUC}^{7}\left({ }^{\circ} \mathrm{C} / 48 \mathrm{~h}\right)$} & 1,891 & 1,896 & 3.79 & 0.37 \\
\hline & \multicolumn{4}{|c|}{$9 \mathrm{~d}$ BEC } \\
\hline & $\mathrm{CON}$ & PS & SEM & $P$-value ${ }^{2}$ \\
\hline $\operatorname{MESOR}\left({ }^{\circ} \mathrm{C}\right)$ & 39.36 & 39.22 & 0.07 & 0.21 \\
\hline Amplitude $\left({ }^{3} \mathrm{C}\right)$ & 0.24 & 0.13 & 0.02 & 0.01 \\
\hline Acrophase $^{4}(\mathrm{~h})$ & 2232 & 0118 & 100 & 0.26 \\
\hline $\mathrm{R}^{25}$ & 0.48 & 0.23 & 0.05 & 0.01 \\
\hline$P$-value ${ }^{6}$ & $<0.05$ & $<0.05$ & 0.01 & 0.18 \\
\hline \multirow[t]{3}{*}{$\operatorname{AUC}^{7}\left({ }^{\circ} \mathrm{C} / 48 \mathrm{~h}\right)$} & 1,909 & 1,902 & 3.61 & 0.21 \\
\hline & \multicolumn{4}{|c|}{14 DIM } \\
\hline & $\mathrm{CON}$ & PS & SEM & $P$-value ${ }^{2}$ \\
\hline $\operatorname{MESOR}\left({ }^{\circ} \mathrm{C}\right)$ & 39.31 & 39.24 & 0.08 & 0.58 \\
\hline Amplitude $\left({ }^{3} \mathrm{C}\right)$ & 0.18 & 0.18 & 0.05 & 1.00 \\
\hline Acrophase $^{4}(\mathrm{~h})$ & 2326 & 2356 & 95 & 0.82 \\
\hline $\mathrm{R}^{25}$ & 0.23 & 0.17 & 0.05 & 0.43 \\
\hline$P$-value ${ }^{6}$ & $<0.05$ & $<0.05$ & 0.01 & 0.44 \\
\hline $\operatorname{AUC}^{7}\left({ }^{\circ} \mathrm{C} / 48 \mathrm{~h}\right)$ & 1,906 & 1,903 & 3.87 & 0.59 \\
\hline
\end{tabular}

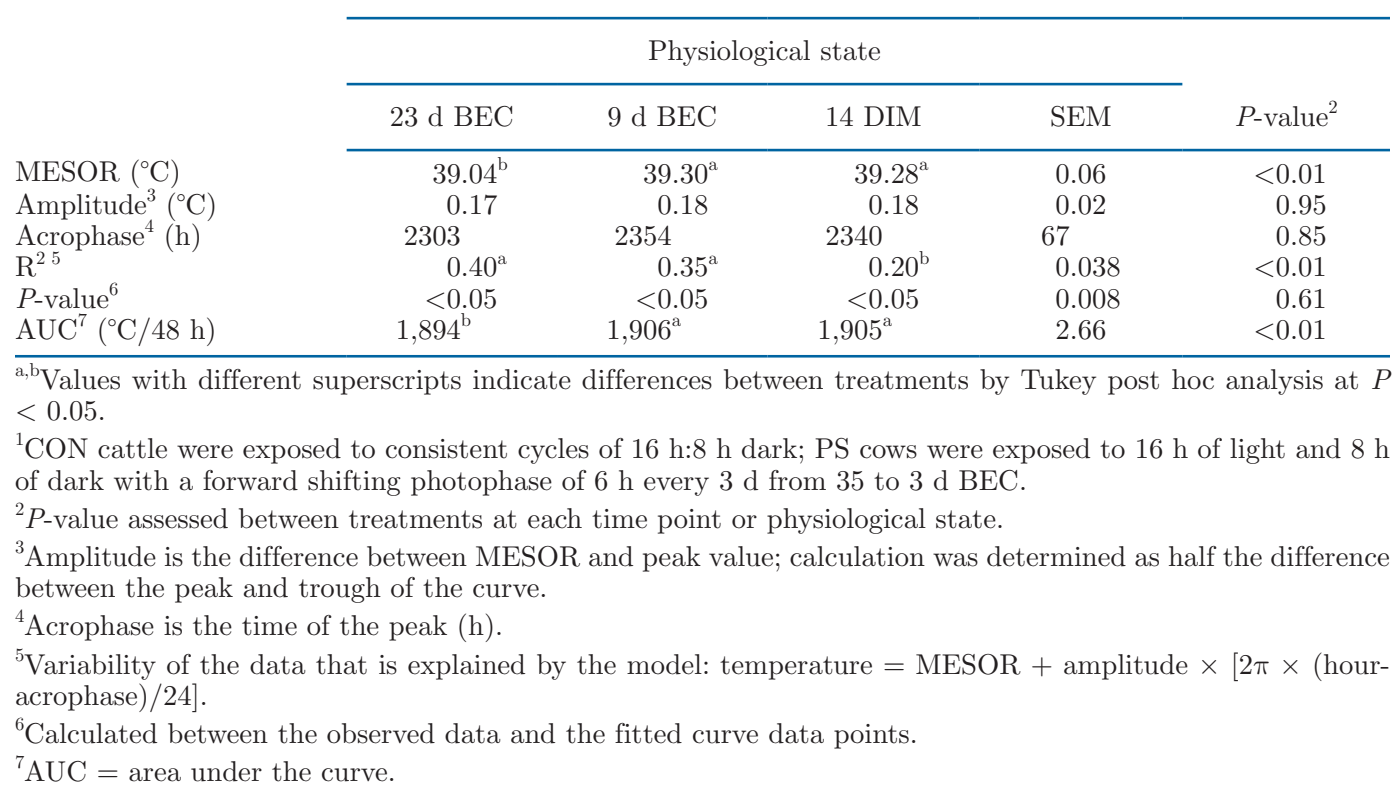

ference was observed in RQUICKI or RQUICKI_BHB between treatments at 7 DIM. Blood glucose, BHB, insulin, and NEFA baseline concentrations were different $(P<0.05)$ between the prepartum and postpartum periods; however, there was no difference in RQUICKI or RQUICKI_BHB between the 2 physiological states.
At $14 \mathrm{~d}$ BEC, there was no difference between treatments in glucose response curves $(P>0.05$; Figure $3 \mathrm{~A})$, glucose clearance rate, glucose $\mathrm{AUC}$, and the time to reach half-maximal glucose postpeak (Table 4). There was a treatment by time effect for the insulin response curve $(P<0.05$; Figure 3B), which resulted in the PS 


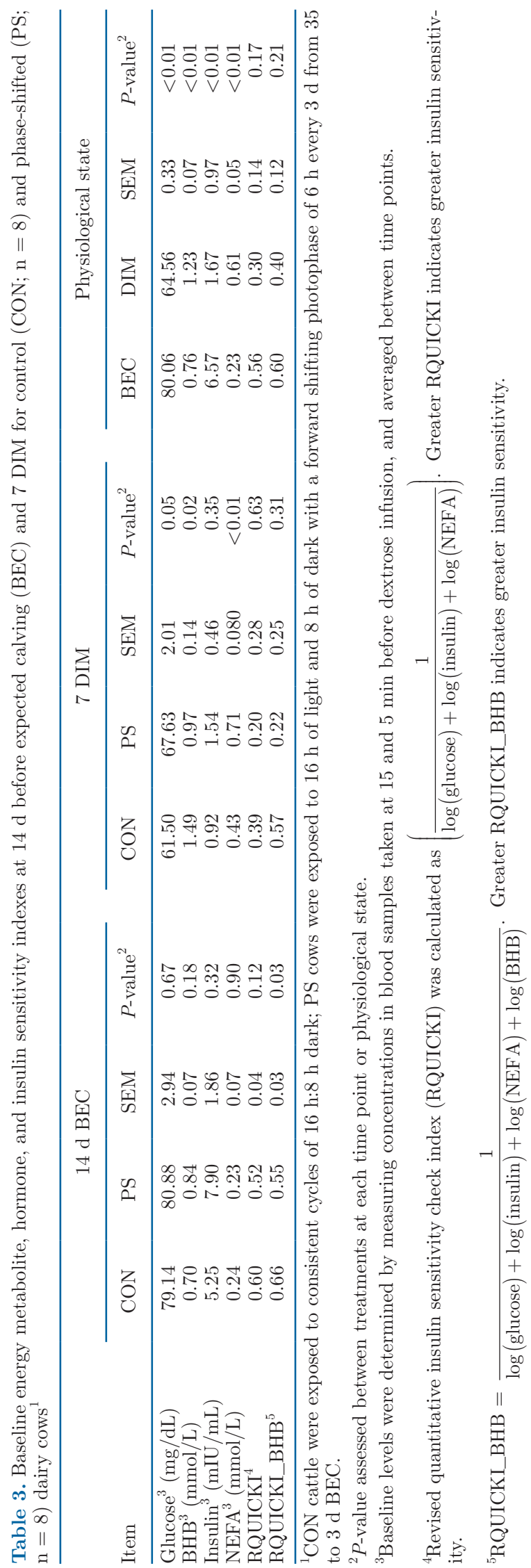

group having greater insulin concentrations at $\mathrm{t}=5$, 10, 15, and 20 min postglucose infusion. The CON treatment had a lower insulin AUC compared with PS $(P=0.05$; Table 4$)$. The PS cows tended to clear insulin at a faster rate than $\operatorname{CON}(P=0.08 ; 3.50$ vs. $2.69 \%$ ), which was calculated by the change per minute in insulin concentration from the time point of peak insulin through 60 min postglucose administration.

Plasma NEFA concentrations over the IVGTT were not statistically different between treatments $(P>$ $0.05)$, nor were there treatment by time effects $(P>$ 0.05; Figure 4A). The PS cows had a tendency for lower BHB concentrations over the IVGTT sampling period ( $P=0.08$; Supplemental Figure S1A; https://doi.org/ 10.3168/jds.2020-19250).

At 7 DIM there was no difference between treatments in glucose concentration at any time point after dextrose infusion (Figure 3C and 3D). Similar to $14 \mathrm{~d}$ $\mathrm{BEC}$, this resulted in no treatment differences in glucose AUC (Table 4), glucose clearance rate, or time to half-maximal glucose. A treatment difference was observed in insulin AUC measurement from 0 to $180 \mathrm{~min}$ $(P=0.03 ; 697$ vs. $1,053 \mathrm{mIU} / \mathrm{mL}$; Table 4$)$, as well as a difference in insulin increment between treatments $(P$ $=0.04 ; 28.8$ vs. $43.5 \mathrm{mIU} / \mathrm{mL}$ ). There was no difference in insulin clearance rate between treatments.

There was a trend for treatment by time point interaction for plasma NEFA concentrations $(P=0.09$; Figure 4B). Both treatments had similar NEFA concentrations at the time of glucose administration, but NEFA concentration tended to be reduced in PS cows at $\mathrm{t}=30,40,50$, and 75 min postglucose infusion and reduced NEFA concentrations at $\mathrm{t}=60 \mathrm{~min}$. The CON cows had greater baseline BHB concentrations, but no overall treatment difference was observed for BHB in the $180 \mathrm{~min}$ postglucose administration (Supplemental Figure S1B; https://doi.org/10.3168/jds.2020-19250).

Comparison of IVGTT variables in cattle between 14 $\mathrm{d}$ BEC and 7 DIM indicated all cows had a greater glucose clearance rate, faster time to half-maximal glucose time point, and lower glucose AUC in the postpartum versus prepartum period (Table 4). Similarly, for insulin metrics, cows in the postpartum period had a lower insulin increment, greater insulin clearance rate, and reduced insulin AUC relative to the prepartum time point.

\section{Mammary Development}

The PS cows had reduced lumen to alveolar area than CON cows at $21 \mathrm{~d}$ BEC $(P<0.05$; 0.086 vs. 0.16 ; Table 5). All cows had a greater lumen to alveolar ratio at 21 DIM compared with $21 \mathrm{~d} \operatorname{BEC}(P<0.05 ; 0.21$ vs. 0.13). The proliferation index of MEC, as indicated 
by the percentage of cells positively stained for KI67, was significantly reduced in PS compared with CON cows at $21 \mathrm{~d}$ BEC $(P<0.05 ; 5.2$ vs. $12.4 \%)$. However, no significant difference was observed in MEC proliferation at 21 DIM between the treatments $(P>0.05$; 0.77 vs. $0.78 \%)$. Rate of epithelial proliferation was significantly higher in the prepartum than postpartum periods. There was no treatment difference in proliferation index of mammary stromal cells, but levels were significantly greater in the prepartum versus postpartum sampling time points $(P<0.05 ; 2.26$ vs. $0.59 \%)$.

\section{DMI}

There was no difference in DMI between treatments during the prepartum or postpartum period (Table 6; Supplemental Figure S2; https://doi.org/10.3168/jds .2020-19250). However, all cattle consumed more DM in the postpartum versus prepartum period $(P<0.05$; 17.1 vs. $12.5 \mathrm{~kg} / \mathrm{d}$ ).
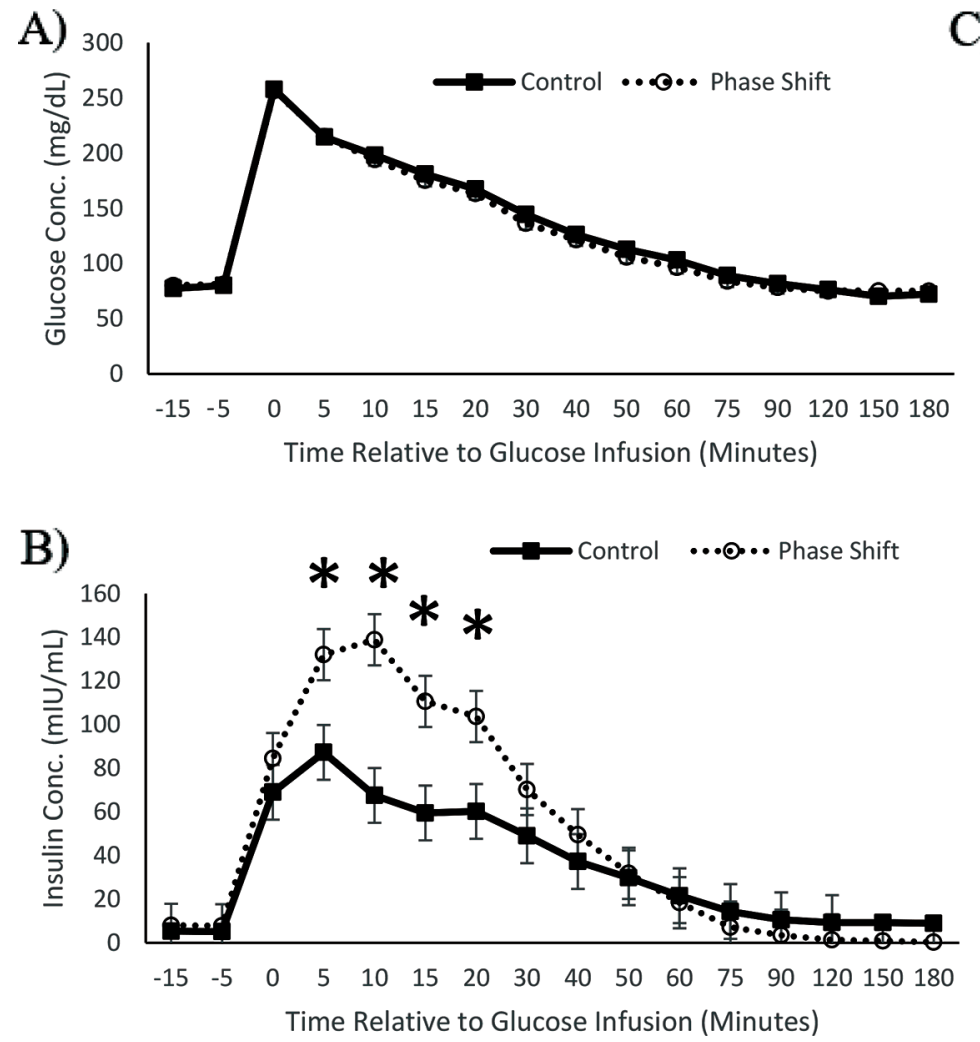

\section{Milk Production and Components}

The PS cows produced less milk than CON cows from 1 to 60 DIM ( $P=0.05 ; 40.3$ vs. $42.6 \mathrm{~kg} / \mathrm{d}$; Table 6 ). A trend was observed for lower milk solids (4.87 vs. $5.30 \mathrm{~kg} / \mathrm{d} ; P=0.10)$ and lactose (1.86 vs. $2.03 \mathrm{~kg} / \mathrm{d}$, $P=0.09)$ in PS cows compared with the CON group across the $5 \mathrm{~d}$ milk components were analyzed. No differences were observed in percent fat and protein yield. The treatments had similar MUN values and SCC.

\section{DISCUSSION}

Multiparous cattle exposed to chronic light-dark phase shifts in late gestation developed insulin resistance, which despite cessation of treatment, was carried over into the postpartum period. Moreover, MEC proliferation at $21 \mathrm{~d}$ BEC and lumen to alveolar ratio was reduced in the PS-treated cattle, indicating that exposure to circadian disruption negatively affected dry
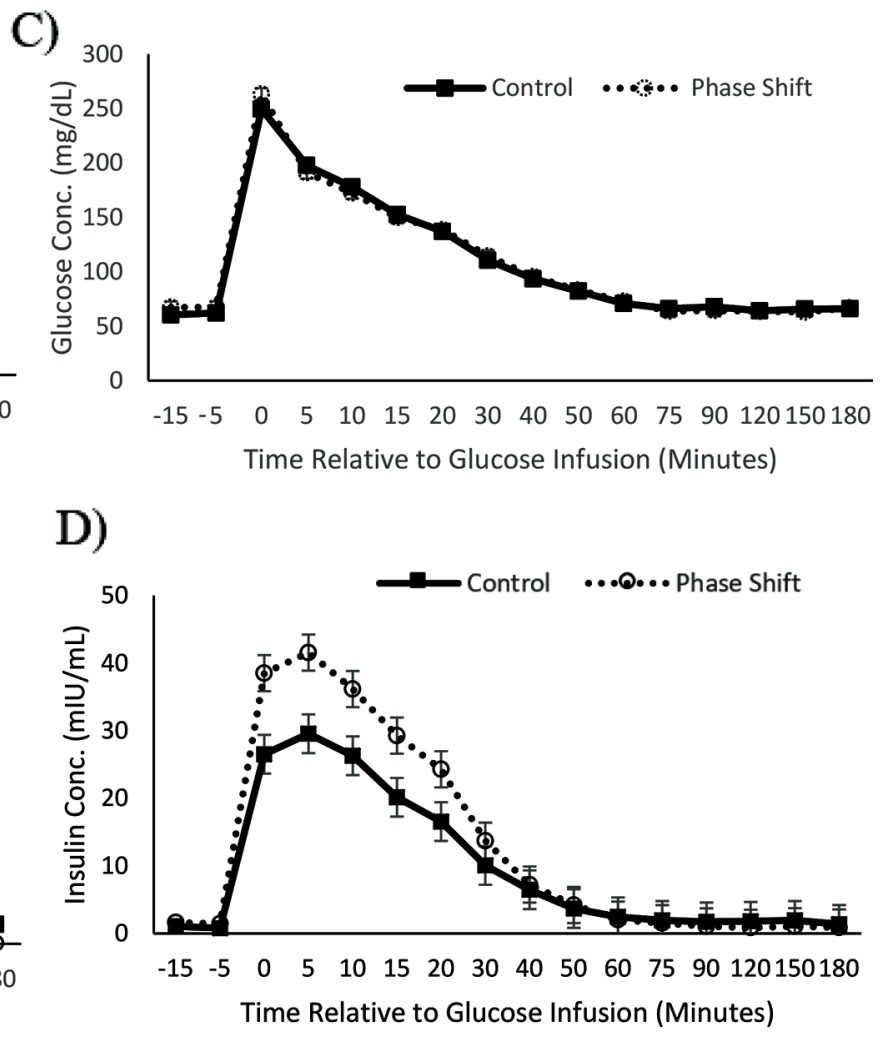

Figure 3. Response curves of blood glucose concentration on (A) $14 \mathrm{~d}$ before expected calving (BEC) and at (C) 7 DIM, and insulin concentration on (B) $14 \mathrm{~d} \mathrm{BEC}$ and at (D) 7 DIM during the intravenous glucose tolerance test in control (solid line) and phase-shifted (occluded, dashed line) dairy cows. The control cattle were exposed to consistent cycles of $16 \mathrm{~h}: 8 \mathrm{~h}$ dark, whereas phase-shifted cows were exposed to 16 $\mathrm{h}$ of light and $8 \mathrm{~h}$ of dark with a forward shifting photophase of $6 \mathrm{~h}$ every $3 \mathrm{~d}$ from 35 to $3 \mathrm{~d}$ BEC. On $14 \mathrm{~d}$ BEC there was no difference in glucose $(P=0.38)$ or insulin $(P=0.19)$ levels between treatments, although there was a treatment by time point interaction for insulin levels, with * indicating a difference $(P=0.05)$ in plasma insulin between treatments at the designated time point. At 7 DIM there was no difference in glucose $(P=0.39)$ or insulin $(P=0.27)$ levels between treatments or treatment $\times$ time point interactions. Conc. $=$ concentration. Error bars represent SEM for LSM of the treatment $\times$ timepoint interaction. 


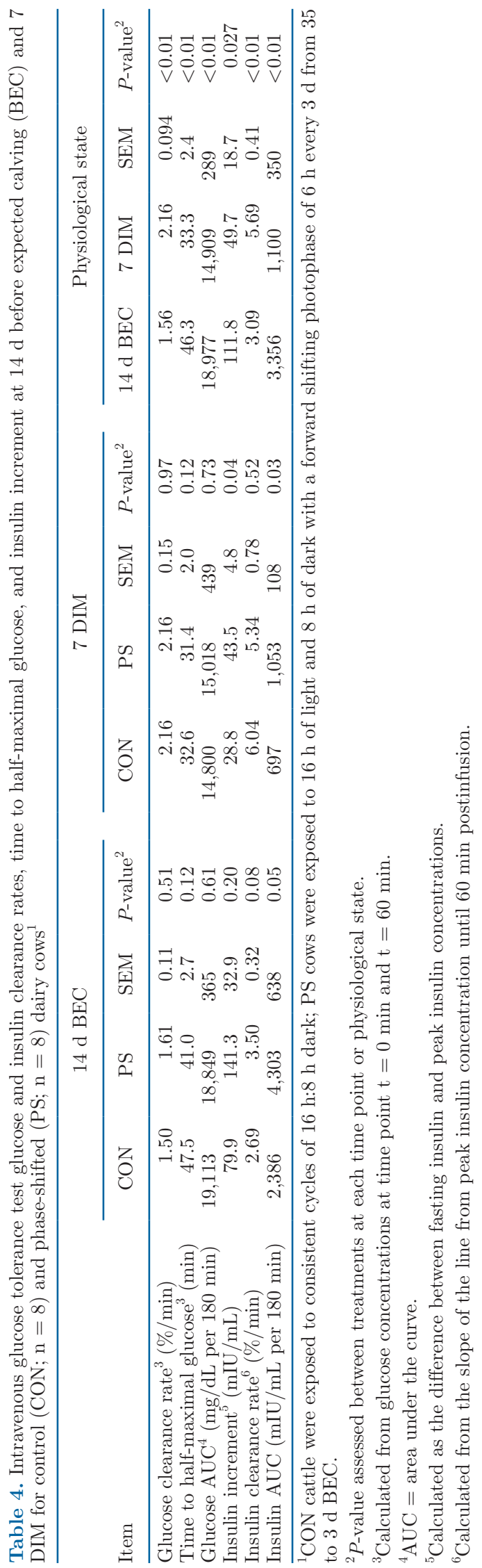

period mammary development. The PS cattle also had reduced milk yield in the first 2 mo of lactation, indicating that circadian rhythm disruptions in late gestation negatively affected subsequent lactation performance.

\section{Circadian Disruption Model Altered Internal Temperature Rhythm}

The forward shifting pattern of light-dark phase was implemented based on previous studies in rodents that showed this chronic jetlag model disrupted the CTS and resulted in alterations in metabolism (Reddy et al., 2002; Filipski et al., 2004). Similar to studies in rodents, we found that exposure to chronic light-dark phase shifts reduced the cosine rhythm of the 24-h body temperature rhythm. Although no difference was observed in fit of core body temperature after 2 wk of exposure to chronic light-dark phase shifts, after 4 wk of exposure, the body temperature circadian rhythmicity of PS cows was attenuated relative to CON. Although there was no treatment difference in amplitude at $23 \mathrm{~d}$ BEC, at $9 \mathrm{~d}$ BEC the PS cows had a lower amplitude at $9 \mathrm{~d}$ BEC compared with the CON group. These findings were similar to our previous study (Suarez-Trujillo et al., 2020) and support that the CTS was disrupted in PS cattle.

Across all cows, temperature MESOR and AUC increased between 23 and $9 \mathrm{~d}$ BEC. These results are in agreement with Suarez-Trujillo et al. (2020), and likely reflect the increased metabolic output as cows transition to lactation (Gamo et al., 2013). At 14 DIM, there was no difference in $\mathrm{R}^{2}$ or amplitude between treatments, and across all cattle $\mathrm{R}^{2}$ was significantly lower than during 23 and $9 \mathrm{~d}$ BEC recording periods. This finding suggests that the physiological adaptations that occur to support lactation may obscure or attenuate endogenously generated rhythms (Jilge et al., 2001).

\section{Circadian Disruptions Affected Insulin Signaling}

Exposure to chronic light-dark phase shift resulted in greater baseline insulin resistance in PS cattle at 14 $\mathrm{d}$ BEC as indicated by significantly lower RQUICKIBHB. A similar discrepancy in RQUICKI-BHB and RQUICKI as indicators of baseline insulin sensitivity was observed by others (Balogh et al., 2008), and thus supports the use of both variables in analysis. In response to the IVGTT, PS cows produced greater insulin than CON cows, resulting in a treatment by time point interaction in insulin concentration, whereas there was no difference between treatments in glucose concentration response curves. The difference in insulin AUC with no difference in glucose AUC in response to the dextrose infusion, is consistent with insulin resis- 
tance in the PS treatment compared with the CON (De Koster and Opsomer, 2013). The finding that cattle develop insulin resistance in response to circadian rhythm disruption is consistent with studies of other species (Turek et al., 2005; Kennaway et al., 2013; Gatford et al., 2019), although it is important to note that the response may be variable (Varcoe et al., 2014).

At 7 DIM, the PS cows exhibited greater insulin production compared with CON cows in response to IVGTT, indicating that the effect of treatment on insulin resistance was carried over into the postpartum period. While the phenomenon of insulin resistance in early lactation enables cows to mobilize adipose tissue stores to support the energetic demands of milk synthesis, very high levels of insulin resistance are postulated to lead to the development of metabolic disorders such as ketosis and fatty liver due to overloading of NEFA, and likewise rapid body condition loss (Zachut et al., 2013). Health indices were not different between treatments in the study (data not shown), although a larger sample of cows would likely be needed to evaluate this outcome.

It is important to note that other studies have observed minimal correlation between baseline indices of insulin sensitivity and IVGTT AUC calculations (De Koster et al., 2016; Alves-Nores et al., 2017). This can be due to several factors that include the time relative to last meal, and physiological state; these baseline indices were created to measure human insulin sensitivity and adapted for cattle (Holtenius and Holtenius, 2007; De Koster et al., 2017; González-Grajales et al., 2017). There is also the concern that insulin disappearance occurs through several insulin-independent pathways including renal filtration and fetal and mammary gland uptake depending on the physiological state of the animal (González-Grajales et al., 2018; Malacco et al., 2020). Although the gold standard of measuring insulin sensitivity in dairy cows has been the use of the insulin euglycemic clamp, several studies have evaluated insulin sensitivity using IVGTT and RQUICKI alone (Pires et al., 2007; Mann et al., 2016). Furthermore, the first $60 \mathrm{~min}$ of an IVGTT in evaluating insulin resistance have been shown to be well correlated with the evaluation of a euglycemic clamp (De Koster et al., 2016). Therefore, although the insulin euglycemic clamp is the ideal measurement, sufficient data are available to suggest that IVGTT and RQUICKI alone can be used to characterize cattle insulin sensitivity.

In accordance with the glucose infusion, both groups demonstrated a marked reduction in plasma NEFA concentrations, which is consistent with findings of others (Schoenberg et al., 2012; Mann et al., 2016; Girard et al., 2019). At 7 DIM, the PS animals tended to have lower NEFA concentrations at 40 to 75 min postglucose infusion, which indicates a greater uptake or reduced mobilization of fatty acids in response to greater insulin production.

\section{Circadian Rhythm Disruptions Compromised MEC Development and Milk Yield}

The number of epithelial cells and metabolic activity of MEC are directly related to milk yield in dairy cattle (Knight, 2000; Capuco and Choudhary, 2020). At $21 \mathrm{~d}$ BEC, the PS animals had lower indexes of MEC proliferation compared with CON cows. Consistent with less epithelial cell proliferation at $21 \mathrm{~d}$ BEC, the lumen:alveolar ratio was lower in PS cattle at $21 \mathrm{~d}$ BEC
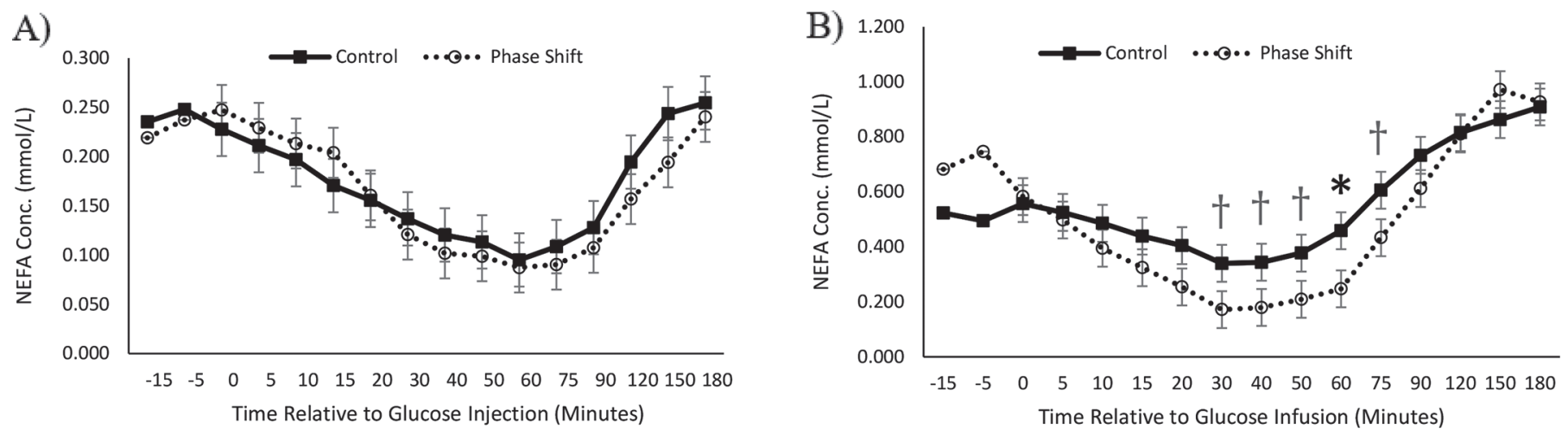

Figure 4. Response curves of blood nonesterified fatty acid (NEFA) concentration on (A) $14 \mathrm{~d}$ before expected calving (BEC) and (B) 7 DIM during the intravenous glucose tolerance test in control (solid line) and phase-shifted (occluded, dashed line) dairy cows. The control cattle were given a consistent $16 \mathrm{~h}$ of light and $8 \mathrm{~h}$ of dark each day, whereas the phase-shifted animals were given $16 \mathrm{~h}$ of light and $8 \mathrm{~h}$ of dark with a forward shifting photophase of 6 h every 3 d from 35 to 3 d BEC. On $14 \mathrm{~d}$ BEC there was no difference in NEFA $(P=0.76)$ levels between treatments. At 7 DIM there was no difference in NEFA $(P=0.25)$ but there was a trend for treatment $\times$ time point interaction $(P=0.09)$, with $*$ indicating a difference $(P=0.05)$ and $\dagger$ indicating a trend $(P<0.10, P>0.05)$ in plasma NEFA at the designated time point levels between treatments or treatment $\times$ time point interactions. Conc. $=$ concentration. Error bars represent SEM for LSM of the treatment $\times$ timepoint interaction. 


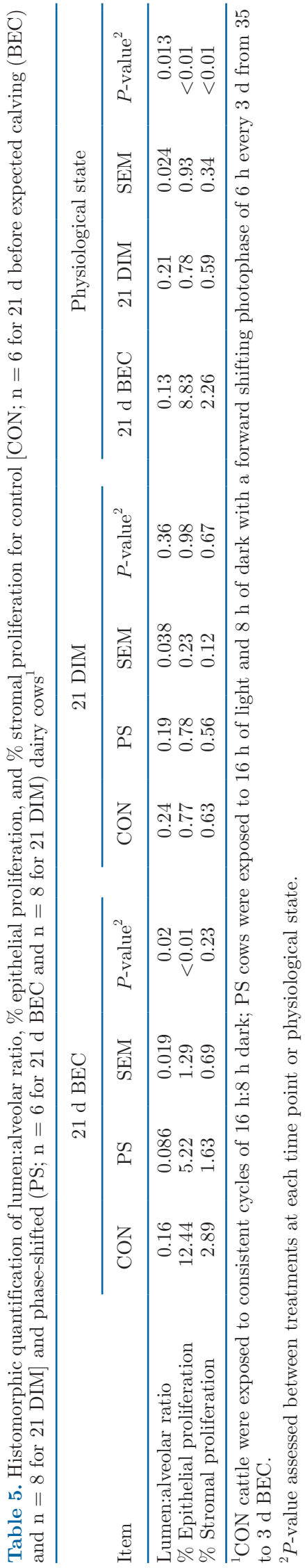

and 21 DIM. Together, these support that exposure to PS treatment in late gestation decreased dry period mammary parenchymal replenishment. The insulin resistance observed in PS cattle prepartum may have played a role in compromised mammary development as insulin is essential for MEC development (Cohick, 2016).

The greater insulin resistance in the postpartum period of PS cattle may have also contributed to lower milk yield, as milk protein synthesis and mammary gland amino acid catabolism are insulin dependent (Menzies et al., 2009; Menzies et al., 2010). In addition, our cell culture and rodent studies demonstrated that circadian clock genes regulate mammary epithelial cell growth and differentiation (Casey et al., 2016). Previous chronodisruption studies of lactating dairy cattle, whether induced by chronic exposure to light-dark phase shifts (Casey et al., 2014) or restricted night feeding (Salfer and Harvatine, 2020), altered the dynamics of core clock gene expression in the mammary gland. The altered expression of core clock genes was related to changes in milk yield in both studies. Therefore, it is also plausible that the mammary clock was altered in the current study in a manner that negatively affected gland development and therefore milk yield.

Also noteworthy is that significant alterations in circadian rhythms of the core body temperature were observed at $9 \mathrm{~d}$ BEC but not at $23 \mathrm{~d}$ BEC. This may be an important point to consider in interpreting the effect of treatment on metabolism and mammary development, as biopsies were taken at $21 \mathrm{~d}$ BEC and

Table 6. Postpartum DMI, milk production, milk component concentration and yield, and melatonin from 1 to 60 DIM for control $(\mathrm{CON} ; \mathrm{n}=8)$ and phase-shifted $(\mathrm{PS} ; \mathrm{n}=8) \mathrm{cows}^{1}$

\begin{tabular}{|c|c|c|c|c|}
\hline \multirow[b]{2}{*}{ Item } & \multicolumn{2}{|c|}{ Treatment } & \multirow[b]{2}{*}{ SEM } & \multirow[b]{2}{*}{$P$-value } \\
\hline & $\mathrm{CON}$ & PS & & \\
\hline${\text { Postpartum } \text { DMI }^{2}(\mathrm{~kg} / \mathrm{d})}$ & 17.4 & 16.7 & 0.70 & 0.46 \\
\hline Milk yield $^{3}(\mathrm{~kg} / \mathrm{d})$ & 42.6 & 40.3 & 0.80 & 0.05 \\
\hline $\mathrm{Fat}^{4}(\mathrm{~kg} / \mathrm{d})$ & 1.66 & 1.52 & 0.07 & 0.15 \\
\hline Protein $^{4}(\mathrm{~kg} / \mathrm{d})$ & 1.20 & 1.13 & 0.04 & 0.24 \\
\hline Lactose $^{4}(\mathrm{~kg} / \mathrm{d})$ & 2.03 & 1.86 & 0.07 & 0.09 \\
\hline Solids $^{4}(\mathrm{~kg} / \mathrm{d})$ & 5.30 & 4.87 & 0.18 & 0.10 \\
\hline $\mathrm{Fat}^{4}(\%)$ & 3.95 & 3.90 & 0.13 & 0.80 \\
\hline Protein $^{4}(\%)$ & 2.85 & 2.90 & 0.05 & 0.48 \\
\hline Lactose $^{4}(\%)$ & 4.76 & 4.71 & 0.05 & 0.51 \\
\hline Solids $^{4}(\%)$ & 12.52 & 12.43 & 0.21 & 0.78 \\
\hline $\operatorname{MUN}^{4}(\mathrm{mg} / \mathrm{dL})$ & 7.87 & 8.22 & 0.29 & 0.57 \\
\hline $\log _{10}$ SCC $^{4}$ & 4.93 & 4.76 & 0.18 & 0.50 \\
\hline
\end{tabular}

${ }^{1} \mathrm{CON}$ cattle were exposed to consistent cycles of $16 \mathrm{~h}: 8 \mathrm{~h}$ dark; PS cows were exposed to $16 \mathrm{~h}$ of light and $8 \mathrm{~h}$ of dark with a forward shifting photophase of $6 \mathrm{~h}$ every $3 \mathrm{~d}$ from 35 to $3 \mathrm{~d}$ before expected calving. ${ }^{2}$ Dry matter intake compiled from 1 to 21 DIM.

${ }^{3}$ Milk yield from 1 to 60 DIM.

${ }^{4}$ Milk composition taken from milk samples on $7,14,21,30$, and 60 DIM. 
IVGTT was performed at $14 \mathrm{~d}$ BEC before differences in temperature circadian rhythm were observed. Factors regulated by circadian clocks exhibit variable response to factors that cause chronodisruption, with some becoming more sensitive or more resistant to changes in the external environment. Rhythms of core body temperature were more resistant to alterations when animals were exposed to factors aimed at forcing desynchrony between internal timing and external regulators (Cambras et al., 2007). Currently, few data are aimed at understanding the sensitivity of the mammary development to circadian disruption; however, studies of metabolic systems suggest they are relatively sensitive to changes in external influences. For example, $8 \mathrm{~d}$ of forced internal desynchronization to misalign circadian clocks in healthy humans increased glucose and insulin levels (Scheer et al., 2009). Nonetheless, half of the participants exhibited a pre-diabetic state during the period of circadian misalignment. Although the timing of the first mammary biopsy and IVGTT were held before the observed misalignment of core body temperature, studies in humans support that alterations in regulations of glucose homeostasis would be evident after 2 wk of exposure to chronic light-dark phase shifts.

Our previous study (Suarez-Trujillo et al., 2020) found exposure of cattle to chronic light-dark phase shifts during late gestation was associated with increased milk yield in the subsequent lactation. At this time, we cannot account for the differential response of cattle to treatments but provide the following to discuss similarities and differences. In the previous study, the overall metabolic response of cattle to the phase shift treatment was decreased circulating glucose levels, without differences in insulin levels in nonfasted states. This relationship suggested treatment increased insulin sensitivity, which we did not observe in our present study. Other studies using sheep also reported differential metabolic response in glucose homeostasis to shifting light-dark photoperiods (Varcoe et al., 2014; Gatford et al., 2019). The former showed no difference in insulin sensitivity and the latter demonstrated insulin resistance under chronic phase shift lighting conditions. Studies in humans and rodents have clearly showed that the circadian system regulates glucose homeostasis (Qian and Scheer, 2016). Model systems developed to study circadian regulation of glucose homeostasis found that behavioral and sleep patterns contribute to the relative response to disruption, with sleep disruption and feeding pattern disruptions exacerbating the insulin resistance response. Genetic studies have found deletion of the core clock gene Bmal1 in various tissues elicits different effects on glucose homeostasis in rodents. For example, when Bmal1 was ablated in the liver, rodents develop hypoglycemia, and whereas ablation in the pancreas resulted in rodents developing insulin resistance, with both responses found to be diet dependent (Qian and Scheer, 2016).

\section{CONCLUSIONS}

Multiparous cattle exposed to chronic light-dark phase shifts for the last 5 wk of gestation had compromised mammary gland development and developed insulin resistance that carried over into the postpartum period after the elimination of treatment. Metabolic alterations and compromised mammary development were associated with decreased milk yield in the subsequent lactation. This work indicates that the CTS plays a role in regulation of glucose homeostasis and mammary development in cattle, and shows the importance of minimizing disturbances in day-to-day activities and environment of cattle and maintaining consistency during late gestation to ensure optimal milk production in early lactation.

\section{ACKNOWLEDGMENTS}

This work is supported by the Agriculture and Food Research Initiative (AFRI) competitive grant no. 2017-67015-26569 project accession no. 1011965 from the USDA National Institute of Food and Agriculture (Washington, DC). The authors acknowledge V. BernalCrespo in the Purdue University Histology Research Laboratory (West Lafayette, IN) and J. Franco in the Metabolite Profiling Facility at the Purdue University Bindley Bioscience Center. The authors also acknowledge the Purdue graduate students T. Hurst, R. Klopp, and L. Beckett for their help with mammary biopsies, as well as visiting scholar of the Animal Science Department V. Malacco and Plaut Laboratory technician K. Huff for their assistance with the IVGTT sample collection. Thanks also go to the undergraduates of Purdue Animal Science, E. Ludwick, M. Keirn, S. Luecke, H. Westfall, and A. Rosenkrans, for their contributions to the project and to M. Grott and the remainder of the staff at the Animal Sciences Research and Education Center for making this work possible. The authors have not stated any conflicts of interest.

\section{REFERENCES}

Alves-Nores, V., C. Castillo, J. Hernandez, and A. Abuelo. 2017. Comparison of surrogate indices for insulin sensitivity with parameters of the intravenous glucose tolerance test in early lactation dairy cattle. Domest. Anim. Endocrinol. 61:48-53. https://doi.org/10 .1016/j.domaniend.2017.06.003.

Balogh, O., O. Szepes, K. Kovacs, M. Kulcsar, J. Reiczigel, J. Alcazar, M. Keresztes, H. Febel, J. Bartyik, S. Gy Fekete, L. Fesus, and G. Huszenicza. 2008. Interrelationships of growth hormone AluI 
polymorphism, insulin resistance, milk production and reproductive performance in Holstein-Friesian cows. Veterinární Medicína 53:604-616.

Bauman, D. E., and W. B. Currie. 1980. Partitioning of nutrients during pregnancy and lactation: A review of mechanisms involving homeostasis and homeorhesis. J. Dairy Sci. 63:1514-1529. https:// doi.org/10.3168/jds.S0022-0302(80)83111-0.

Bell, A. W., W. S. Burhans, and T. R. Overton. 2000. Protein nutrition in late pregnancy, maternal protein reserves and lactation performance in dairy cows. Proc. Nutr. Soc. 59:119-126. https:// doi.org/10.1017/S0029665100000148.

Burdick, N. C., J. A. Carroll, J. W. Dailey, R. D. Randel, S. M. Falkenberg, and T. B. Schmidt. 2012. Development of a self-contained, indwelling vaginal temperature probe for use in cattle research. J. Therm. Biol. 37:339-343. https://doi.org/10.1016/j.jtherbio.2011 .10.007.

Buxton, O. M., S. W. Cain, S. P. O'Connor, J. H. Porter, J. F. Duffy, W. Wang, C. A. Czeisler, and S. A. Shea. 2012. Adverse metabolic consequences in humans of prolonged sleep restriction combined with circadian disruption. Sci. Transl. Med. 4:129ra43. https://doi .org/10.1126/scitranslmed.3003200.

Cambras, T., J. R. Weller, M. Angles-Pujoras, M. L. Lee, A. Christopher, A. Diez-Noguera, J. M. Krueger, and H. O. de la Iglesia. 2007. Circadian desychronization of core body temperature and sleep stages in the rat. Proc. Natl. Acad. Sci. USA 104:7634-7639. https://doi.org/10.1073/pnas.0702424104.

Capuco, A. V., R. M. Akers, and J. J. Smith. 1997. Mammary growth in Holstein cows during the dry period: Quantification of nucleic acids and histology. J. Dairy Sci. 80:477-487.

Capuco, A. V., and R. K. Choudhary. 2020. Symposium review: Determinants of milk production: Understanding population dynamics in the bovine mammary epithelium. J. Dairy Sci. 103:2928-2940.

Casey, T., J. Crodian, S. S. Donkin, and K. Plaut. 2014. Continuously changing light-dark phase decreases milk yield, fat, protein and lactose in dairy cows. J. Adv. Dairy Res. 2:2. https://doi.org/10 .4172/2329-888X.1000119.

Casey, T., J. Crodian, A. Suárez-Trujillo, E. Erickson, B. Weldon, K. Crow, S. Cummings, Y. Chen, A. Shamay, S. J. Mabjeesh, and K. Plaut. 2016. CLOCK regulates mammary epithelial cell growth and differentiation. Am. J. Physiol. Regul. Integr. Comp. Physiol. 311:R1125-R1134. https://doi.org/10.1152/ajpregu.00032.2016.

Casey, T., H. Sun, H. J. Burgess, J. Crodian, S. Dowden, S. Cummings, K. Plaut, D. Haas, L. Zhang, and A. Ahmed. 2019. Delayed lactogenesis II is associated with lower sleep efficiency and greater variation in nightly sleep duration in the third trimester. J. Hum. Lact. 35:713-724. https://doi.org/10.1177/0890334419830991.

Cohick, W. S. 2016. Physiology and Endocrinology Symposium: Effects of insulin on mammary gland differentiation during pregnancy and lactation. J. Anim. Sci. 94:1812-1820. https://doi.org/ 10.2527/jas.2015-0085.

Collier, R. J., G. E. Dahl, and M. J. Vanbaale. 2006. Major advances associated with environmental effects on dairy cattle. J. Dairy Sci. 89:1244-1253. https://doi.org/10.3168/jds.S0022-0302(06)72193 -2 .

Dahl, G. E. 2008. Effects of short day photoperiod on prolactin signaling in dry cows: A common mechanism among tissues and environments? J. Anim. Sci. 86(suppl_13):10-14. https://doi.org/10 $.2527 /$ jas.2007-0311.

De Koster, J., M. Hostens, K. Hermans, W. Van den Broeck, and G. Opsomer. 2016. Validation of different measures of insulin sensitivity of glucose metabolism in dairy cows using the hyperinsulinemic euglycemic clamp test as the gold standard. Domest. Anim. Endocrinol. 57:117-126. https://doi.org/10.1016/j.domaniend.2016 .06 .004 .

De Koster, J., M. Van Eetvelde, K. Hermans, W. Van den Broeck, M. Hostens, and G. Opsomer. 2017. Short communication: Limitations of glucose tolerance tests in the assessment of peripheral tissue insulin sensitivity during pregnancy and lactation in dairy heifers. J. Dairy Sci. 100:2381-2387. https://doi.org/10.3168/jds 2016-11792.
De Koster, J. D., and G. Opsomer. 2013. Insulin resistance in dairy cows. Vet. Clin. North Am. Food Anim. Pract. 29:299-322. https: //doi.org/10.1016/j.cvfa.2013.04.002.

De Vries, L. D., H. Dover, T. Casey, M. J. VandeHaar, and K. Plaut. 2010. Characterization of mammary stromal remodeling during the dry period. J. Dairy Sci. 93:2433-2443. https://doi.org/10 $.3168 /$ jds.2009-2764.

DeVries, T. J., S. Dufour, and D. T. Scholl. 2010. Relationship between feeding strategy, lying behavior patterns, and incidence of intramammary infection in dairy cows. J. Dairy Sci. 93:1987-1997. https://doi.org/10.3168/jds.2009-2692.

Dolatshad, H., E. A. Campbell, L. O'hara, E. S. Maywood, M. H. Hastings, and M. H. Johnson. 2006. Developmental and reproductive performance in circadian mutant mice. Hum. Reprod. 21:68 79. https://doi.org/10.1093/humrep/dei313.

Duffield, T. F., K. D. Lissemore, B. W. McBride, and K. E. Leslie. 2009. Impact of hyperketonemia in early lactation dairy cows on health and production. J. Dairy Sci. 92:571-580. https://doi.org/ $10.3168 /$ jds.2008-1507.

Facco, F. L., C. B. Parker, U. M. Reddy, R. M. Silver, M. A. Koch, J. M. Louis, R. C. Basner, J. H. Chung, C.-L. Nhan-Chang, G. W. Pien, S. Redline, W. A. Grobman, D. A. Wing, H. N. Simhan, D. M. Haas, B. M. Mercer, S. Parry, D. Mobley, S. Hunter, G. R. Saade, F. P. Schubert, P. C. Zee, and F. Facco. 2017. Association between sleep-disordered breathing and hypertensive disorders of pregnancy and gestational diabetes mellitus. Obstet. Gynecol. 129:31-41. https://doi.org/10.1097/AOG.0000000000001805.

Filipski, E., F. Delaunay, V. M. King, M. W. Wu, B. Claustrat, A. Gréchez-Cassiau, C. Guettier, M. H. Hastings, and L. Francis. 2004. Effects of chronic jet lag on tumor progression in mice. Cancer Res. 64:7879-7885. https://doi.org/10.1158/0008-5472.CAN $-04-0674$.

Gamo, Y., C. Troup, S. E. Mitchell, C. Hambly, L. M. Vaanholt, and J. R. Speakman. 2013. Limits to sustained energy intake. XX. Body temperatures and physical activity of female mice during lactation. J. Exp. Biol. 216:3751-3761. https://doi.org/10.1242/ jeb.090308.

Gangwisch, J. E. 2009. Epidemiological evidence for the links between sleep, circadian rhythms and metabolism. Obes. Rev. 10:37-45. https://doi.org/10.1111/j.1467-789X.2009.00663.x.

Gatford, K. L., D. J. Kennaway, H. Liu, D. O. Kleemann, T. R. Kuchel, and T. J. Varcoe. 2019. Simulated shift work disrupts maternal circadian rhythms and metabolism, and increases gestation length in sheep. J. Physiol. 597:1889-1904. https://doi.org/ 10.1113/JP277186.

Girard, C. L., N. Vanacker, V. Beaudet, M. Duplessis, and P. Lacasse. 2019. Glucose and insulin responses to an intravenous glucose tolerance test administered to feed-restricted dairy cows receiving folic acid and vitamin B12 supplements. J. Dairy Sci. 102:62266234. https://doi.org/10.3168/jds.2019-16298.

González-Grajales, L.A., L. Pieper, J. Kremer, and R. Staufenbiel. 2017. Influence of food deprivation on intravenous glucose tolerance test traits in Holstein Friesian heifers. J. Dairy Sci. 100:77107719. https://doi.org/10.3168/jds.2016-12133.

González-Grajales, L. A., L. Pieper, S. Mengel, and R. Staufenbiel. 2018. Evaluation of glucose dose on intravenous glucose tolerance test traits in Holstein-Friesian heifers. J. Dairy Sci. 101:774-782. https://doi.org/10.3168/jds.2017-13215.

Herring, S. J., D. B. Nelson, G. W. Pien, C. Homko, L. M. Goetzl, A. Davey, and G. D. Foster. 2014. Objectively measured sleep duration and hyperglycemia in pregnancy. Sleep Med. 15:51-55. https: //doi.org/10.1016/j.sleep.2013.07.018.

Holtenius, P., and K. Holtenius. 2007. A model to estimate insulin sensitivity in dairy cows. Acta Vet. Scand. 49:29. https://doi.org/ 10.1186/1751-0147-49-29.

Hoshino, K., Y. Wakatsuki, M. Iigo, and S. Shibata. 2006. Circadian clock mutation in dams disrupts nursing behavior and growth of pups. Endocrinology 147:1916-1923. https://doi.org/10.1210/en .2005-1343. 
Hurley, W. L. 1989. Symposium: Mammary gland function during involution and the declining phase of lactation. Mammary gland function during involution. J. Dairy Sci. 72:1637-1646.

Jilge, B., B. Kuhnt, W. Landerer, and S. Rest. 2001. Circadian temperature rhythms in rabbit pups and in their does. Lab Anim. 35:364-373. https://doi.org/10.1258/0023677011911831.

Kennaway, D. J.., M. J. Boden, and A. Voultsios. 2004. Reproductive performance in female Clock(Delta19) mutat mice. Reprod. Fertil. Dev. 16:801-810. https://doi.org/10.1071/RD04023.

Kennaway, D. J., T. J. Varcoe, A. Voultsios, and M. J. Boden. 2013. Global loss of Bmall expression alters adipose tissue hormones, gene expression and glucose metabolism. PLoS One 8:e65255. https://doi.org/10.1371/journal.pone.0065255.

Kerestes, M., V. Faigl, M. Kulcsár, O. Balogh, J. Földi, H. Fébel, Y. Chilliard, and G. Huszenicza. 2009. Periparturient insulin secretion and whole-body insulin responsiveness in dairy cows showing various forms of ketone pattern with or without puerperal metritis. Domest. Anim. Endocrinol. 37:250-261. https://doi.org/10.1016/j .domaniend.2009.07.003.

Kessler, E. C., S. K. Wall, L. L. Hernandez, J. J. Gross, and R. M. Bruckmaier. 2019. Short communication: Mammary gland tight junction permeability after parturition is greater in dairy cows with elevated circulating serotonin concentrations. J. Dairy Sci. 102:1768-1774. https://doi.org/10.3168/jds.2018-15543.

Knight, C. H. 2000. The importance of cell division in udder development and lactation. Livest. Prod. Sci. 66:169-176. https://doi.org/ 10.1016/S0301-6226(00)00224-4.

Mabjeesh, S. J., C. Sabastian, O. Gal-Garber, and A. Shamay. 2013. Effect of photoperiod and heat stress in the third trimester of gestation on milk production and circulating hormones in dairy goats. J. Dairy Sci. 96:189-197. https://doi.org/10.3168/jds.2012-5624.

Malacco, V. M. R., M. Erickson, F. F. Cardoso, B. P. Biese, J. G. Laguna, and S. S. Donkin. 2020. Short communication: Effect of glucose infusion dose and stage of lactation on glucose tolerance test kinetics in lactating dairy cows. J. Dairy Sci. 103:7547-7554. https://doi.org/10.3168/jds.2019-17139.

Mann, S., F. A. L. Yepes, M. Duplessis, J. J. Wakshlag, T. R. Overton, B. P. Cummings, and D. V. Nydam. 2016. Dry period plane of energy: Effects on glucose tolerance in transition dairy cows. J. Dairy Sci. 99:701-717. https://doi.org/10.3168/jds.2015-9908.

Menzies, K. K., H. J. Lee, C. Lefèvre, C. J. Ormandy, K. L. Macmillan, and K. R. Nicholas. 2010. Insulin, a key regulator of hormone responsive milk protein synthesis during lactogenesis in murine mammary explants. Funct. Integr. Genomics 10:87-95. https://doi .org/10.1007/s10142-009-0140-0.

Menzies, K. K., C. Lefèvre, K. L. Macmillan, and K. R. Nicholas. 2009. Insulin regulates milk protein synthesis at multiple levels in the bovine mammary gland. Funct. Integr. Genomics 9:197-217. https: //doi.org/10.1007/s10142-008-0103-x.

Mohawk, J. A., C. B. Green, and J. S. Takahashi. 2012. Central and peripheral circadian clocks in mammals. Annu. Rev. Neurosci. 35:445-462. https://doi.org/10.1146/annurev-neuro-060909 $-153128$.

Nakagawa, H., and N. Okumura. 2010. Coordinated regulation of circadian rhythms and homeostasis by the suprachiasmatic nucleus. Proc. Jpn. Acad. B Phys. Biol. Sci. 86:391-409. https://doi.org/ 10.2183/pjab.86.391

Pires, J. A. A., A. H. Souza, and R. R. Grummer. 2007. Induction of hyperlipidemia by intravenous infusion of tallow emulsion causes insulin resistance in Holstein cows. J. Dairy Sci. 90:2735-2744. https://doi.org/10.3168/jds.2006-759.

Qian, J., and F. A. J. L. Scheer. 2016. Circadian system and glucose metabolism: Implications for physiology and disease. Trends Endocrinol. Metab. 27:282-293. https://doi.org/10.1016/j.tem.2016 .03 .005 .

Reddy, A. B., M. D. Field, E. S. Maywood, and M. H. Hastings. 2002. Differential resynchronisation of circadian clock gene expression within the suprachiasmatic nuclei of mice subjected to experimental jet lag. J. Neurosci. 22:7326-7330. https://doi.org/10.1523/ JNEUROSCI.22-17-07326.2002.
Reppert, S. M., and D. R. Weaver. 2002. Coordination of circadian timing in mammals. Nature 418:935-941. https://doi.org/10.1038/ nature00965.

Salfer, I. J., and K. Harvatine. 2020. Night-restricted feeding of dairy cows modifies daily rhythms of feed intake, milk synthesis and plasma metabolites compared to day-restricted feeding. Br. J. Nutr. 123:849-858. https://doi.org/10.1017/S0007114520000057.

Scheer, F. A. J. L., M. F. Hilton, C. S. Mantzoros, and S. A. Shea. 2009. Adverse metabolic and cardiovascular consequences of circadian misalignment. Proc. Natl. Acad. Sci. USA 106:4453-4458. https://doi.org/10.1073/pnas.0808180106.

Schoenberg, K. M., R. M. Ehrhardt, and T. R. Overton. 2012. Effects of plane of nutrition and feed deprivation on insulin responses in dairy cattle during late gestation. J. Dairy Sci. 95:670-682. https: //doi.org/10.3168/jds.2011-4529.

Stenvers, D. J., F. A. J. L. Scheer, P. Schrauwen, S. E. la Fleur, and A. Kalsbeek. 2019. Circadian clocks and insulin resistance. Nat. Rev. Endocrinol. 15:75-89. https://doi.org/10.1038/s41574-018-0122-1.

Suarez-Trujillo, A., G. Wernert, H. Sun, T. S. Steckler, K. Huff, S. Cummings, J. Franco, R. N. Klopp, J. R. Townsend, M. Grott, J. S. Johnson, K. Plaut, J. P. Boerman, and T. M. Casey. 2020. Exposure to chronic light-dark phase shifts during the prepartum nonlactating period attenuates circadian rhythms, decreases blood glucose, and increases milk yield in the subsequent lactation. J. Dairy Sci. 103:2784-2799. https://doi.org/10.3168/jds.2019-16980.

Turek, F. W., C. Joshu, A. Kohsaka, E. Lin, G. Ivanova, E. Mcdearmon, A. Laposky, S. Olson, A. Easton, D. R. Jensen, R. H. Eckel, J. S. Takahashi, and J. Bass. 2005. Obesity and metabolic syndrome in circadian clock mutant mice. Science 308:1043-1045. https://doi.org/10.1126/science.1108750.

Valenzuela, F. J., J. Vera, C. Venegas, F. Pino, and C. Lagunas. 2015. Circadian system and melatonin hormone: Risk factors for complications during pregnancy. Obstet. Gynecol. Int. 2015:825802. https://doi.org/10.1155/2015/825802.

Van Soest, P. J., J. B. Robertson, and B. A. Lewis. 1991. Methods for dietary fiber, neutral detergent fiber, and nonstarch polysaccharides in relation to animal nutrition. J. Dairy Sci. 74:3583-3597. https://doi.org/10.3168/jds.S0022-0302(91)78551-2.

Varcoe, T. J., K. L. Gatford, A. Voultsios, M. D. Salkeld, M. J. Boden, L. Rattanatray, and D. J. Kennaway. 2014. Rapidly alternating photoperiods disrupt central and peripheral rhythmicity and decrease plasma glucose, but do not affect glucose tolerance or insulin secretion in sheep. Exp. Physiol. 99:1214-1228. https://doi .org/10.1113/expphysiol.2014.080630.

Wall, E. H., T. L. Auchtung, G. E. Dahl, S. E. Ellis, and T. B. McFadden. 2005. Exposure to short day photoperiod during the dry period enhances mammary growth in dairy cows. J. Dairy Sci. 88:1994-2003. https://doi.org/10.3168/jds.S0022-0302(05)72875 -7 .

Zachut, M., H. Honig, S. Striem, Y. Zick, S. Boura-Halfon, and U. Moallem. 2013. Periparturient dairy cows do not exhibit hepatic insulin resistance, yet adipose-specific insulin resistance occurs in cows prone to high weight loss. J. Dairy Sci. 96:5656-5669. https: //doi.org/10.3168/jds.2012-6142.

Zhao, X., B. Ponchon, S. Lanctôt, and P. Lacasse. 2019. Invited review: Accelerating mammary gland involution after drying-off in dairy cattle. J. Dairy Sci. 102:6701-6717. https://doi.org/10.3168/ jds.2019-16377.

\section{ORCIDS}

A. Suarez-Trujillo @ https://orcid.org/0000-0002-9343-5016

K. A. Teeple $\odot$ https://orcid.org/0000-0002-3127-5002

T. M. Casey ๑ https://orcid.org/0000-0002-8835-3550

J. P. Boerman (ㄴ https://orcid.org/0000-0002-0336-8295 